\title{
$\beta$-lactoglobulin micro- and nanostructures as bioactive compounds vehicle: In vitro studies
}

\author{
Lívia S. Simões ${ }^{\mathrm{a}}$, Joana T. Martins ${ }^{\mathrm{a}}$, Ana C. Pinheiro ${ }^{\mathrm{a}}$, António A. Vicente ${ }^{\mathrm{a}}$, Oscar L. Ramos ${ }^{\mathrm{b}, *}$ \\ ${ }^{\text {a } C E B ~-~ C e n t r e ~ o f ~ B i o l o g i c a l ~ E n g i n e e r i n g, ~ U n i v e r s i t y ~ o f ~ M i n h o, ~ C a m p u s ~ d e ~ G u a l t a r, ~ 5710-057 ~ B r a g a, ~ P o r t u g a l ~}$ \\ ${ }^{\text {b } C B Q F-C e n t r o ~ d e ~ B i o t e c n o l o g i a ~ e ~ Q u i ́ m i c a ~ F i n a, ~ E s c o l a ~ S u p e r i o r ~ d e ~ B i o t e c n o l o g i a, ~ U n i v e r s i d a d e ~ C a t o ́ l i c a ~ P o r t u g u e s a / P o r t o, ~ P o r t o ~ 4169-005, ~ P o r t u g a l ~}$
}

\section{A R T I C L E I N F O}

\section{Keywords:}

Bioaccessibility

Bioavailability

Caco-2 cells

Delivery systems

Hydrophilic compounds

Hydrophobic compounds

Food-grade

\begin{abstract}
A B S T R A C T
$\beta$-Lactoglobulin $(\beta-\mathrm{Lg})$ is known to be capable to bind hydrophilic and hydrophobic bioactive compounds. This research aimed to assess the in vitro performance of $\beta$ - $\mathrm{Lg}$ micro- (diameter ranging from 200 to $300 \mathrm{~nm}$ ) and nano (diameter $<100 \mathrm{~nm}$ ) structures associated to hydrophilic and hydrophobic model compounds on Caco-2 cells and under simulated gastrointestinal (GI) conditions. Riboflavin and quercetin were studied as hydrophilic and hydrophobic model compounds, respectively. Cytotoxicity experiment was conducted using in vitro cellular model based on human colon carcinoma Caco- 2 cells. Moreover, the digestion process was simulated using the harmonized INFOGEST in vitro digestion model, where samples were taken at each phase of digestion process oral, gastric and intestinal - and characterized in terms of particle size, polydispersity index (PDI), surface charge by dynamic light scattering (DLS); protein hydrolysis degree by 2,4,6-trinitrobenzene sulfonic acid (TNBSA) assay and native polyacrylamide gel electrophoresis; and bioactive compound concentration. Caco- 2 cell viability was not affected up to $21 \times 10^{-3} \mathrm{mg} \mathrm{mL}^{-1}$ of riboflavin and $16 \times 10^{-3} \mathrm{mg} \mathrm{mL}^{-1}$ quercetin on $\beta$ - $\mathrm{Lg}$ micro- and nanostructures. In the oral phase, $\beta$-Lg structures' particle size, PDI and surface charge values were not changed comparing to the initial $\beta$-Lg structures (i.e., before being subjected to in vitro GI digestion). During gastric digestion, $\beta$ - $\mathrm{Lg}$ structures were resistant to proteolytic enzymes and to acid environment of the stomach confirmed by TNBSA and native gel electrophoresis. In vitro digestion results indicated that $\beta$-Lg micro- and nanostructures protected both hydrophilic and hydrophobic compounds from gastric conditions and deliver them to target site (i.e., intestinal phase). In addition, $\beta$-Lg structures were capable to enhance riboflavin and quercetin bioaccessibility and bioavailability potential compared to bioactive compounds in their free form. This study indicated that $\beta$-Lg micro- and nanostructures were capable to enhance hydrophilic and hydrophobic compounds bioavailability potential and they can be used as oral delivery systems.
\end{abstract}

\section{Introduction}

The steady interest on the improvement of food quality and human health led to a growing use of bioactive compounds level in food products (Chen, Zou, Liu, \& McClements, 2016). Commonly, challenges regarding to their inclusion in food products are attributed to the poor solubility (e.g., hydrophobic compounds) in food matrices and their instability along the digestion process (Bourbon, Pinheiro, Cerqueira, \& Vicente, 2018). Thus, to overcome these factors, designing of an appropriate bio-based system to transport and deliver bioactive compounds to a specific target site is of utmost importance (Gonçalves, Martins, Duarte, Vicente, \& Pinheiro, 2018).

$\beta$-lactoglobulin $(\beta-\mathrm{Lg})$ is one the most abundant whey proteins (ca. $50-60 \%$ ) present in bovine serum (Samadarsi \& Dutta, 2019). This protein has nutritional and functional features (e.g., gelation capacity) which allows the formation of structures with distinct properties and morphologies (Ramos et al., 2012). These characteristics enable its use as an oral vehicle system of bioactive compounds in food products (Singh \& Sarkar, 2011). Our previous results demonstrated that $\beta-\mathrm{Lg}$ samples, purified from a commercial whey protein isolate through a well-published method, exhibited a similar level of purity when compared to a commercial $\beta-\mathrm{Lg}$ fraction, were able to form $\beta$ - $\mathrm{Lg}$ micro(with diameters between of 200 and $300 \mathrm{~nm}$ ) and nano (diameters $\leq 100 \mathrm{~nm}$ ) structures (Simões, Araújo, Vicente, \& Ramos, 2020). Also, these structures successfully associated hydrophilic (i.e., riboflavin) and hydrophobic (i.e., quercetin) bioactive compounds, and were able to maintain their stability, when subjected to various environmental conditions, and to release both bioactive compounds, in

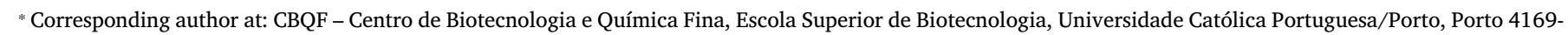
005, Portugal.

E-mail address: os.silva.ramos@gmail.com (O.L. Ramos). 
two food simulants with different hydrophobicities under different temperatures $\left(4{ }^{\circ} \mathrm{C}\right.$ and $25{ }^{\circ} \mathrm{C}$ ) (Simões, Abrunhosa, Vicente, \& Ramos, 2020). Despite all these findings, more information is needed to understand the behaviour of $\beta$-Lg micro- and nanostructures with bioactive compounds associated under gastrointestinal (GI) tract conditions. Caco-2 cells derived from human colon adenocarcinoma gain a prominence in in vitro assays because they mimic the absorption of the bioactive compound across the epithelial membrane and they can be used for toxicological assessment (Tibolla et al., 2019; Tibolla, Pelissari, Martins, Vicente, \& Menegalli, 2018). Moreover, $\beta$-Lg micro- and nanostructures need to assure bioactive compounds' bioaccessibility in the gastrointestinal (GI) tract to exert their bioactivity at a specific target tissue (Rein et al., 2012). Therefore, in vitro digestion models (Pinheiro et al., 2013; Pinheiro, Gonçalves, Madalena, \& Vicente, 2017) were used as a tool for understanding the influence of complex physicochemical and physiological processes on $\beta$-Lg bio-based structures and on the release of bioactive compounds from those structures when they pass through the different regions of the GI tract.

Few in vitro studies were found in the literature regarding $\beta$-Lg structures associated with bioactive compounds. Madalena et al. (2016) evaluated the effect of encapsulating riboflavin into $\beta$ - $L g$ nanostructures on riboflavin bioavailability upon a static in vitro GI digestion. These authors concluded that $\beta-\mathrm{Lg} /$ riboflavin nanostructures act as a vehicle for riboflavin until it reaches the intestine (i.e., target site), where the protein degradation occurs. Moreover, they demonstrated that $12 \%$ of riboflavin recommended daily dose reached the intestine if $100 \mathrm{~mL}$ of a food simulant solution was ingested. Le Maux, Brodkorb, Croguennec, and Hennessy (2013) investigated the potential changes in $\beta$ - $\mathrm{Lg} /$ linoleate complex after static in vitro digestion, as well as the linoleate acid bioaccessibility and their intracellular transport into Caco2 cells. These authors demonstrated that binding $\beta$ - $\mathrm{Lg}$ to linoleic acid influences the protein susceptibility to digestion. Also, $\beta$ - Lg was capable to modify linoleic acid transport and metabolism on Caco-2 cells. Although these researches had underlined the importance of the in vitro studies, there is limited information available regarding the in vitro simulated mouth phase and the use of other bioactive compounds in such structures. Moreover, information is very scarce or inexistent about the potential effect of different $\beta$ - $\mathrm{Lg}$ particle size structures - micro (diameters between 200 and $300 \mathrm{~nm}$ ) and nano (diameters $\leq 100 \mathrm{~nm}$ ) - on the bioavailability potential of bioactive compounds with different solubilities. In this sense, the harmonized INFOGEST in vitro digestion model was used in this study once which mimics the main in vivo physiological digestion conditions (i.e., temperature, $\mathrm{pH}$, ionic strength and residence time), has a simple and standard methodology, and allows the comparison with other researches who use the same procedure. The present work intends to provides information about the potential cytotoxicity on Caco- 2 cell monolayer of $\beta$ - $\mathrm{Lg}$ micro- and nanostructures either isolated or associated to riboflavin and quercetin, used as hydrophilic and hydrophobic, respectively, model compounds. Bioaccessibility and bioavailability potential of both bioactive model compounds were assessed when such compounds were associated to and compared $\beta$ - $\mathrm{Lg}$ micro- and nanostructures and compared when they were present in their free form. Additionally, $\beta$ - $\mathrm{Lg}$ micro- and nanostructures hydrolysates during in vitro GI tract were evaluated. The final intention is to provide useful information about the impact of $\beta$ - $\mathrm{Lg}$ micro- and nanostructures on the oral bioavailability of bioactive compounds with distinct solubilities.

\section{Materials and methods}

\subsection{Feedstocks and chemicals}

The following chemicals were purchased from Sigma-Aldrich (St. Louis, MO, USA): quercetin ( $\geq 95 \%$, HPLC), riboflavin ( $\geq 98 \%$,), sodium azide, ANS (8-Anilino-1-napththalenesulfonic), sodium phosphate tribasic dodecahydrate $98 \%$, sodium dodecyl sulfate (SDS), tris (hydroxymethyl)aminomethane, ammonium persulfate (APS), Coomassie Brilliant Blue (R-250), bromophenol blue, etramethylethylenediamine, pancreatin from porcine pancreas, pepsin from porcine gastric mucosa, bile extract porcine, pefabloc ${ }^{\circledR}$ SC, 4-(2-aminoetyl) benenesulfonyl fluoride, sodium and ammonium carbonate, potassium phosphate dibasic, magnesium chloride, penicillin-streptomycin, trypsin-EDTA solution (0.25\%), methylthiazolyldiphenyl-tetrazolium (MTT) and celLytic ${ }^{\mathrm{TM}}$ MT cell lysis reagent. Acrylamide was purchased from Bio-Rad (California, USA) and glycerol was obtained from Himedia (Mumbai, India). Acetic and phosphoric acids, sodium hydroxide were purchased from Merck (Merck KGaA, Darmstadt, Germany). Potassium and calcium chloride, hydrochloric acid, monosodium phosphate, sodium chloride and glycine were obtained from Panreac (Barcelona, Spain). Methanol and phosphate dibasic were purchased from Chem-Lab (Zedelgem, Belgium) whereas dimethyl sulfoxide was obtained from Fisher Scientific (New Hampshire, USA). Serine was purchased from Acros Organics (Belgium) whereas TNBSA (2,4,6-Trinitrobenzene Sulfonic Acid) was obtained from Thermo Fisher Scientific (Bremen, Germany). Caco-2 cell line, obtained from human colon carcinoma, was kindly supplied by Department of Biology of University of Minho (Braga, Portugal). Dulbecco's Modified Eagle Medium (DMEM) with L-glutamine, fetal bovine serum, non-essential amino acids was purchased from Lonza (Basel, Switzerland). Hanks' Balanced Salt solution (HBSS) was purchased from Biochrom GmbH (Berlin, Germany) and others cell culture reagents were purchased from Biowest (Nuaillé, France). All other chemicals used in this study were reagent grade, and were used without further purification.

\subsection{Development of $\beta$ - Lg micro- and nanostructures}

Food grade $\beta$-Lg micro- and nanostructures associated with bioactive model compounds were prepared as described on Simões, Abrunhosa, et al. (2020). Briefly, $\beta$-Lg powder at 5 and $15 \mathrm{mg} \mathrm{mL}^{-1}$ was used to develop nano- and microstructures, respectively, which was solubilized in sodium phosphate buffer at $\mathrm{pH}$ 6. The $\mathrm{pH}$ values of solutions were adjusted with $0.5 \mathrm{~mol} \mathrm{~L}^{-1} \mathrm{H}_{3} \mathrm{PO}_{4}$ or $1 \mathrm{~mol} \mathrm{~L}^{-1} \mathrm{NaOH}$, as necessary. $\beta$ - $\mathrm{Lg}$ solutions were continuously stirred at $400 \mathrm{rpm}$ during $2 \mathrm{~h}$ at room temperature $\left(25^{\circ} \mathrm{C}\right)$. Then, resulting solutions were stored overnight at refrigeration temperature $\left(5^{\circ} \mathrm{C}\right)$ to enable a full protein rehydration. The $\beta$ - $\mathrm{Lg}$ solutions were filtered through a $0.2 \mu \mathrm{m}$ membrane filter (VWR International, USA) and subsequently, heated at $80^{\circ} \mathrm{C}$ for $15 \mathrm{~min}$ under continuously stirring on a temperature controlled water bath (MR Hei-Tec + Pt 1000, Heidolph). After 15 min, a given volume of model bioactive compounds was added to the $\beta$ - $\mathrm{Lg}$ solutions. Riboflavin (hydrophilic model compound), previously dissolved in $0.1 \mathrm{~mol} \mathrm{~L}^{-1} \mathrm{Na}_{3} \mathrm{PO}_{4}$ and protected from light, was added to $\beta$-Lg solution to obtain structures with final concentration of $0.105 \mathrm{mg} \mathrm{mL}^{-1}$ riboflavin. Quercetin (hydrophobic model compound) was solubilized in ethanol and added to the $\beta$ - $\mathrm{Lg}$ solutions to achieve $0.08 \mathrm{mg} \mathrm{mL}^{-1}$ quercetin concentration. Resulting solutions were cooled in ice for 10 min. According to our previous results (Simões, Abrunhosa, et al., 2020), $\beta$-Lg/quercetin nanostructures formed precipitates after 2 days of storage, independently of the storage temperature tested. $\beta-\mathrm{Lg} / \mathrm{ri}$ boflavin micro- and nanostructures and $\beta$ - $\mathrm{Lg}$ /quercetin microstructures showed the best performance in terms of stability (Simões, Abrunhosa, et al., 2020). For this reason, these structures were used on the subsequent in vitro studies performed in this work. $\beta$ - Lg micro- and nanostructures without associated bioactive compounds were used as control samples.

\section{3. $\beta$ - $\mathrm{Lg}$ micro- and nanostructures effect on Caco-2 cells}

The in vitro cellular model based on human colon carcinoma Caco-2 cells was applied to assess $\beta$ - Lg structures cytotoxicity. 


\subsubsection{Cell culture}

Human colon carcinoma Caco-2 cell line was grown in DMEM supplemented with $10 \%$ heat inactivated fetal bovine serum, $1 \%$ penicillin-streptomycin, $1 \%$ L-glutamine and $1 \%$ non-essential amino acids. Caco- 2 cell line was used between passages $60-68$. Stocks cells were maintained in culture flasks incubated at $37{ }^{\circ} \mathrm{C}$ with $5 \% \mathrm{CO}_{2}$ humidified atmosphere. Upon reaching approximately $90 \%$ of confluence, cells were harvested from culture flasks using trypsin-EDTA $(0.25 \%)$. Viable cell number in suspension was carried out by counting in a Neubauer chamber with an optical microscope (Tibolla et al., 2018).

\subsubsection{Cytotoxicity assay}

Cytotoxicity test on Caco- 2 cells were performed by MTT conversion assay (Braz et al., 2017; Ren et al., 2018), according to Tibolla et al. (2019) procedure. Briefly, $\beta$ - $\mathrm{Lg}$ micro- $\left(24 \times 10^{-3}\right.$ to $\left.13.5 \mathrm{mg} \mathrm{mL}^{-1}\right)$, nanostructures $\left(1-4.5 \mathrm{mg} \mathrm{mL}^{-1}\right), \beta-\mathrm{Lg}$ micro- and nanostructures associated to riboflavin $\left(21 \times 10^{-3}\right.$ to $94.5 \times 10^{-3} \mathrm{mg} \mathrm{mL}^{-1}$ riboflavin), $\beta$ - $\mathrm{Lg}$ micro- and nanostructures associated to quercetin $\left(0.128 \times 10^{-3}\right.$ to $40 \times 10^{-3} \mathrm{mg} \mathrm{mL}^{-1}$ quercetin), free bioactive model compounds and ethanol (in equivalent quercetin concentrations) were diluted in supplemented DMEM medium and homogenized. Caco2 cells suspension in supplemented DMEM medium were seeded at a cell density of $4 \times 10^{4}$ cells/well in 96-well plate and incubated at $37{ }^{\circ} \mathrm{C}$ in $5 \% \mathrm{CO}_{2}$ atmosphere during $24 \mathrm{~h}$. Cells only with DMEM was used as control. Subsequently, DMEM medium was replaced by $\beta$ - $\mathrm{Lg}$ samples, free bioactive compounds and ethanol and maintained at $37{ }^{\circ} \mathrm{C}$ in $5 \% \mathrm{CO}_{2}$ during $24 \mathrm{~h}$. After incubation, the samples were removed and cells were washed with PBS. Then, $100 \mu \mathrm{L}$ MTT solution (0.5 mg mL ${ }^{-1}$ in DMEM supplemented) was added into each well and the plate was incubated at $37^{\circ} \mathrm{C}$ for $4 \mathrm{~h}$, in order to form soluble purple formazan crystals. The crystals solubilization was performed by adding $200 \mu \mathrm{L}$ of DMSO to each well followed by plate orbital shaken (100 rpm) during $30 \mathrm{~min}$. The purple formazan was quantified by measurement of the absorbance at $570 \mathrm{~nm}$ and $690 \mathrm{~nm}$ (used for background subtraction) in Synergy ${ }^{\mathrm{TM}}$ HT Multi-mode Microplate Reader (Biotek Instruments, Winooski, VT, USA). The percentage of cell viability for all samples was assessed by Eq. (1).

Cell viability $(\%)=\frac{A_{\text {sample }}}{A_{\text {control }}} \times 100$

where $A_{\text {sample }}$ is the absorbance value of sample with cell culture and $A_{\text {control }}$ is the absorbance value of DMEM with cell culture.

\subsection{Gastrointestinal (GI) model}

\subsubsection{In vitro digestion}

The in vitro digestion experiment was carried out using the harmonized INFOGEST in vitro digestion model to mimic mouth, stomach, and small intestine conditions as described by Minekus et al. (2014). Simulated salivary fluid (SSF), simulated gastric fluid (SGF) and simulated intestinal fluid (SIF) were the electrolyte stock solutions (ca. $1.25 \times$ concentrated) used during in vitro digestion (Table 1 ).

Before in vitro digestion procedure, electrolyte stock solutions and $\beta$ $\mathrm{Lg}$ micro- and nanostructures samples $(5 \mathrm{~mL})$ were inserted in a water bath under constant shaking $\left(37^{\circ} \mathrm{C}, 120\right.$ horizontal strokes/min).

Initially, samples were exposed to simulated mouth conditions (SSF solution) and $\mathrm{CaCl}_{2}\left(\mathrm{H}_{2} \mathrm{O}\right)_{2}$ ) (to achieve the concentration of $1.5 \mathrm{mmol}$ $\mathrm{L}^{-1}$ in fluid). Then, the final oral phase volume was adjusted with milli$\mathrm{Q}$ water and samples were returned to shaking water bath and incubated at $37{ }^{\circ} \mathrm{C}$ for $2 \mathrm{~min}$. Note that $\alpha$-amylase was not used since the samples do not contained starch. After oral phase, a sample was taken and cooled in ice.

Subsequently, the passage through to stomach was mimicked by adding porcine pepsin solution (with an activity of $2000 \mathrm{U} \mathrm{mL}^{-1}$ in the final mixture), SGF solution and $\mathrm{CaCl}_{2}\left(\mathrm{H}_{2} \mathrm{O}\right)_{2}$ (to achieved $0.15 \mathrm{mmol}$
Table 1

Composition of simulated salivary fluid (SSF), simulated gastric fluid (SGF) and simulated intestinal fluid (SIF) stock solutions.

\begin{tabular}{llll}
\hline & SSF $\left(\mathrm{mmol} \mathrm{L}^{-1}\right)$ & SGF $\left(\mathrm{mmol} \mathrm{L}^{-1}\right)$ & SIF $\left(\mathrm{mmol} \mathrm{L}^{-1}\right)$ \\
\hline $\mathrm{KCl}$ & 15.10 & 6.90 & 6.80 \\
$\mathrm{KH}_{2} \mathrm{PO}_{4}$ & 3.70 & 0.90 & 0.80 \\
$\mathrm{NaHCO}_{3}$ & 13.60 & 25.00 & 85.00 \\
$\mathrm{MgCl}_{2}\left(\mathrm{H}_{2} \mathrm{O}\right)_{6}$ & 0.15 & 0.12 & 0.33 \\
$\left(\mathrm{NH}_{4}\right)_{2} \mathrm{CO}_{3}$ & 0.06 & 0.50 & - \\
$\mathrm{NaCl}$ & - & 47.20 & 38.40 \\
$\mathrm{HCl}$ & - & 15.60 & 8.40
\end{tabular}

NOTE: $\mathrm{CaCl}_{2}\left(\mathrm{H}_{2} \mathrm{O}\right)_{2}$ was added to the final of each fluid mixture of digestion to avoid precipitation.

$\mathrm{L}^{-1}$ in the fluid). The $\mathrm{pH}$ value was adjusted to 3.0 with $1 \mathrm{~mol} \mathrm{~L}^{-1} \mathrm{HCl}$, when necessary, and the gastric phase volume was complete with milli$\mathrm{Q}$ water. Samples were incubated at $37{ }^{\circ} \mathrm{C}$ during $2 \mathrm{~h}$. After gastric phase, a sample was taken and cooled in ice.

After $2 \mathrm{~h}$, intestinal phase secretion composed by SIF solution, $\mathrm{CaCl}_{2}\left(\mathrm{H}_{2} \mathrm{O}\right)_{2}$ (to achieved $0.6 \mathrm{mmol} \mathrm{L}^{-1}$ in the fluid,) pancreatin (with an activity of $100 \mathrm{U} \mathrm{mL}^{-1}$ in the final mixture) and bile solutions (in order to reach the concentration of $10 \mathrm{mmol} \mathrm{L}^{-1}$ in the final mixture) (both prepared in SIF) were added to the gastric phase volume. The $\mathrm{pH}$ value was adjusted to 7.0 with $1 \mathrm{~mol} \mathrm{~L}^{-1} \mathrm{NaOH}$, when necessary. The final intestinal phase volume was adjusted with milli-Q water and then, incubated under the same conditions as before for $2 \mathrm{~h}$. In the end of intestinal phase, the reaction was stopped by adding $1 \mathrm{mmol} \mathrm{L}^{-1}$ of enzyme inhibitor pefabloc ${ }^{\circledR}$ SC.

During in vitro digestion samples were collected after each phase (i.e., oral, gastric and intestinal) and cooled in ice before measurements. Samples were tested in the in vitro digestion model at least in triplicate.

\subsubsection{Bioactive model compounds bioaccessibility and bioavailability potential}

Riboflavin and quercetin potential bioavailable fractions were assessed using the method described by Pinheiro et al. (2013) with some modifications. Briefly, intestinal phase samples of the $\beta$-Lg structures $(10 \mathrm{~mL})$ were centrifuged (Allegra 64R, Beckman Coulter, USA) at 18 $000 \mathrm{~g}$ during $30 \mathrm{~min}$ at $25{ }^{\circ} \mathrm{C}$. Following centrifugation, samples were separated in two distinct phases, being at bottom an opaque sediment phase and at the top a clear micelle phase. It was assumed that the model bioactive compounds were in the clear micelle phase (i.e., the bioaccessible fraction) which was available to be absorbed and metabolic processed (Silva et al., 2018). Then, aliquots (5 mL) of micelle phase (supernatant) were collected and used to quantify the amount of bioactive compound released after in vitro digestion. Riboflavin concentration was determined by fluorescence spectroscopy according to the methodology described in Section 2.8.1. Fluorescence intensity was corrected by blank fluorescence subtraction (i.e., in vitro digestion without $\beta-\mathrm{Lg} /$ riboflavin micro- and nanostructures). Quercetin quantification was determined by high performance liquid chromatography with fluorescence detection (HPLC-FL). Briefly, quercetin samples were diluted in DMSO and centrifuged (Mikro 120, Andreas Hettich GmbH \& Co.KG, Tuttlingen, Germany) at $13000 \mathrm{~g}$ during $10 \mathrm{~min}$ at $25{ }^{\circ} \mathrm{C}$. The supernatant was dissolved in methanol to precipitate the protein and centrifuged again at same conditions. Then, resulting sample was filtered through a $0.22 \mu \mathrm{m}$ nylon filter before analysis described in Section 2.8.2. Riboflavin and quercetin bioaccessibility (Eq. (2)), and bioavailability potential (Eq. (3)) were determined as reported by Liu, Wang, McClements, and Zou (2018) using the following equations:

Bioaccessibility $(\%)=\frac{C_{\text {Micelle }} \text { Phase }}{C_{\text {Intestinal Phase }}} \times 100$ 


$$
\begin{aligned}
\text { Bioavailability potential }(\%) & =\frac{C_{\text {Micelle Phase }}}{C_{\text {Intestinal Phase }}} \times \frac{C_{\text {Intestinal Phase }}}{C_{\text {Initial }}} \\
& =\frac{C_{\text {Micelle Phase }}}{C_{\text {Initial }}} \times 100
\end{aligned}
$$

where $C_{\text {Micellephase }}$ is the concentration of bioactive model compounds in the micelle phase, $C_{\text {IntestinalPhase }}$ is the concentration of bioactive model compounds after in vitro digestion, and $C_{\text {Initial }}$ was the initial model bioactive compounds concentration added into the $\beta$ - $\mathrm{Lg}$ structures.

\subsection{Monitoring protein hydrolysis degree during in vitro digestion}

In order to evaluate $\beta$ - $\mathrm{Lg}$ micro- and nanostructures hydrolysis degree $(H D)$ during in vitro digestion, TNBSA assay was performed according to Castillo, Mendez, Al-Azzam, Barletta, and Griebenow (2006). A sample $(0.5 \mathrm{~mL})$ of each in vitro digestion phase was diluted directly in $0.1 \mathrm{~mol} \mathrm{~L}^{-1}$ bicarbonate buffer at $\mathrm{pH} 8.5$ to achieve final protein concentration between 0.05 and $0.2 \mathrm{mg} \mathrm{mL}^{-1}$. Subsequently, $0.25 \mathrm{~mL}$ of $0.1 \%$ TBNSA was added to the resulting solution $(0.5 \mathrm{~mL})$ and incubated at $37{ }^{\circ} \mathrm{C}$ during $2 \mathrm{~h}$. Then, $0.25 \mathrm{~mL}$ of $10 \% \mathrm{SDS}$ and $1 \mathrm{~mol} \mathrm{~L}^{-1}$ $\mathrm{HCl}$ was added to each sample and homogenized. Considering the potential interference of the pepsin from the gastric juice and pancreatin from intestinal phase, in vitro digestion without sample was used as blank. Sample absorbance measurements were carried out at $335 \mathrm{~nm}$ in Synergy $^{\mathrm{TM}}$ HT Multi-mode Microplate Reader (Biotek Instruments, Winooski, VT, USA). All samples were analysed in triplicate and the amino group content was performed by reference serine standard curve $\left(y=0.0207 x+0.0236 ; R^{2}=0.99\right.$; being $y$ and $x$ the absorbance and concentration of serine, respectively). The $H D$ was referred according to the percentage of peptide bond cleaved in the total number of peptide bonds (Luo, Boom, \& Janssen, 2015), as shown in Eq. (4).

$H D(\%)=\left(\frac{h_{\text {sample }}}{h_{\text {total }}}\right) \times 100$

where $h_{\text {sample }}$ is the number of peptide bonds cleaved in sample after each in vitro gastrointestinal phase and $h_{\text {total }}$ is the total number of peptide bond after intestinal phase.

\subsection{Native polyacrylamide gel electrophoresis (Native-PAGE)}

Native-PAGE or "non-denaturing" gel electrophoresis was performed to evaluate $\beta$ - $\mathrm{Lg}$ structures integrity during in vitro digestion. The electrophoresis analysis was carried out using Mini-Protean II dual slab cell system equipped with a PAC 300 power supply (Bio-Rad Laboratories, Hercules, CA, USA), according to Madalena et al. (2016) methodology. The resolving and stacking gel contained $12.5 \%$ and 3.5 $\%$ of polyacrylamide, respectively. The gels were stained and maintained in Coomassie Brilliant Blue (R-250) solution, composed by $50 \%$ methanol and $10 \%$ acid acetic, and maintained overnight with gentle agitation. Afterwards, gels were destained with solution constituted by $30 \%$ methanol and $7 \%$ acetic acid. Standard marker protein PageRuler Unstained Broad Range Protein Ladder (Thermo Scientific) was used to identify samples by their molecular weight.

\subsection{Particle size, polydispersity index and surface charge measurements}

Particles size, polydispersity index (PDI) and surface charge (S) of $\beta$ $\mathrm{Lg}$ micro- and nanostructures dispersions were performed by DLS (Zetasizer Nano ZS, Malvern Instruments, UK) equipped with He-Ne laser at a wavelength of $633 \mathrm{~nm}$, at $25^{\circ} \mathrm{C}$. The intestinal phase of in vitro digestion was diluted prior to analysis at a ratio of 1:50 (v/v) in milli-Q water to avoid multiple scattering effects. All samples measurements were performed at least in triplicate with nine successive measurements. The results were reported as the mean \pm standard deviation.

\subsection{Determination of bioactive model compounds concentration}

\subsubsection{Riboflavin - hydrophilic model compound}

The riboflavin concentration was evaluated by fluorescence measurement using microplate reader with excitation wavelength at

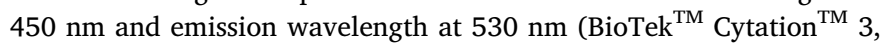
USA). The emission wavelength corresponded to the maximum fluorescence intensity of riboflavin. Standard solutions of riboflavin were used to establish an appropriate calibration curve ( $y=60,293 x+143.8 ; R^{2}=0.99$; where $y$ and $x$ were the fluorescence and riboflavin concentration, respectively).

\subsubsection{Quercetin - hydrophobic model compound}

Quercetin concentration was conducted by high performance liquid chromatography with fluorescence detection (HPLC-FL). The HPLC system used consisted of a Varian Prostar 210 pump, a Varian Prostar 410 autosampler, and a Jasco FP-920 detector. The column used was a C18 column reversed-phase YMC-Pack ODS $(4.6 \times 250 \mathrm{~mm}$ i.d; $5 \mu \mathrm{m}$ particle size). The mobile phase was composed of acetonitrile and distillate water $(40: 60, v / v)$, and was pumped at a flow rate of $1.0 \mathrm{~mL} \mathrm{~min}{ }^{-1}$. The wavelengths used for quercetin detection were $355 \mathrm{~nm}$ (excitation) and $525 \mathrm{~nm}$ (emission) (Komori, Inoue, Fujita, Kasajima, \& Horii, 2007). Quantification was determined according to the standard curve of peak area versus quercetin concentration (ranging from 0 to $0.10 \mathrm{mg} \mathrm{mL}^{-1}$ ) with a correlation coefficient of 0.99 .

\subsection{Statistical procedures}

All experiments were carried out at least in triplicate and data were expressed as the average \pm standard deviation (SD). The statistical analysis was performed by One-way analysis variance (ANOVA) coupled with Tukey post-hoc test with a significance level of $5 \%$ $(p \leq 0.05)$ using Statistica package software version 10.0.228.8 (StatSoft Inc., Tulsa, OK, USA).

\section{Results and discussion}

\section{1. $\beta$-Lg micro- and nanostructures effect on cell viability}

It is important to assess riboflavin and quercetin cytotoxicity once the presence of toxic substances may causes damage to cells and leads to losses in the efficiency of bioactive compounds absorption loss (Sedaghat Doost et al., 2019). However, it was reported that bile salts compounds (i.e., glycine and taurine conjugates of cholic acid or deoxycholic acid sodium salt mixtures) may be toxic to cells, leading to DNA damage (Benedetti et al., 1997; Yi, Zhong, Zhang, Yokoyama, \& Zhao, 2015). In this sense, the potential cytotoxicity of initial (i.e., before in vitro digestion) of $\beta$-Lg micro- and nanostructure samples with and without riboflavin and quercetin were evaluated on Caco- 2 cells after $24 \mathrm{~h}$ of exposure (Fig. 1).

Fig. 1A showed the potential adverse effect of $\beta$ - $\mathrm{Lg}$ micro- and nanostructures with or without riboflavin and free riboflavin on Caco-2 cells. Overall, the cell viability decreased as the exposure concentration increased ( $p \leq 0.05)$. According to the literature, $\beta$ - $\mathrm{Lg}$ is a Generally Recognized As Safe (GRAS) bio-based material (Ramos et al., 2017; Tavares, Ramos, \& Malcata, 2017) ( and riboflavin is an essential compound for the human body (Madadlou, Floury, Pezennec, \& Dupont, 2018; Madalena et al., 2016; O'Neill et al., 2015). Thus, the adverse effect of such structures could be related to their concentration. Caco-2 cell exposure to increased riboflavin and quercetin concentrations presumably indicated an enhance compounds cellular uptake leading to lysosomes saturation, DNA cells impairment and injured membrane (Tibolla et al., 2018).

$\beta-\mathrm{Lg}$ microstructures without bioactive compounds showed a cell viability between 25.6 and $82.0 \%$, whereas $\beta$ - $\mathrm{Lg}$ nanostructures' demonstrated a cell viability of ca. 39.5 to $58.5 \%$ ( $p \leq 0.05$ ) (for 




Fig. 1. Caco-2 cell viability in contact to $\beta-\mathrm{Lg} /$ riboflavin micro- and nano-structures (A) and $\beta$ - $\mathrm{Lg}$ /quercetin micro-structures (B) after $24 \mathrm{~h}$ incubation (bars represent standard deviation). ${ }^{\text {a,b,c,d }}$ Values with different letter superscripts for the same compound concentration were statistically different ( $p \leq 0.05)$. The asterisk $\left.{ }^{*}\right)$ indicates significant difference $(p \leq 0.05)$ relative to the control.



riboflavin equivalent concentration ranging from 31.5 to $94.5 \times 10^{-3}$ $\mathrm{mg} \mathrm{mL}^{-1}$ ) (Fig. 1A). Possibly, the particles' size may have an adverse effect on the cellular uptake of $\beta$ - $L g$ structures in Caco-2 cells. Structures at nanoscale have a large surface area per unit, which can possibly increase the adherence and interaction with cell membranes, leading to an enhanced cellular uptake of nanostructures (Ha, Kim, Lee, Jun, \& Lee, 2015; Quintanilla-Carvajal et al., 2010), and consequently, to a higher cell cytotoxicity.

On the other hand, cytotoxicity results revealed that $\beta-\mathrm{Lg} /$ riboflavin micro- and nanostructures at equivalent concentrations ranging from 52.5 to $73.5 \times 10^{-3} \mathrm{mg} \mathrm{mL}^{-1}$ of riboflavin did not significantly decrease Caco-2 cell viability as compared to the control group (ca. $100 \%$ cell viability) $(p>0.05)$. This behaviour may be attributed to riboflavin protective effect against the possible toxicity caused by $\beta-\mathrm{Lg}$ micro- and nanostructures, since the result of the interaction between $\beta$ $\mathrm{Lg}$ and riboflavin may generate reactive radical and oxygen species (Diarrassouba, Liang, Remondetto, \& Subirade, 2013a). $\beta$-Lg micro- and nanostructures with riboflavin associated (Fig. 1A) at concentration of $21 \times 10^{-3} \mathrm{mg} \mathrm{mL}^{-1}$ showed cell viabilities higher than $90 \%$ for all samples tested. This result $\left(21 \times 10^{-3} \mathrm{mg} \mathrm{mL}^{-1}\right.$ riboflavin $)$ indicated that $\beta$ - $\mathrm{Lg} /$ riboflavin microstructures $\left(12.8 \times 10^{-3} \mathrm{mg} \mathrm{mL}^{-1} \beta\right.$ - $\mathrm{Lg} \mathrm{mi}-$ crostructures) and $\beta$ - $\mathrm{Lg} /$ riboflavin nanostructures $\left(16.9 \times 10^{-3} \mathrm{mg}\right.$ $\mathrm{mL}^{-1} \beta$-Lg nanostructures) did not cause damage to cells.

Regarding quercetin cell viability (Fig. 1B), all samples tested showed $100 \%$ cell viability until $16 \times 10^{-3} \mathrm{mg} \mathrm{mL}^{-1}$ of quercetin. However, increased concentrations up to $40 \times 10^{-3} \mathrm{mg} \mathrm{mL}^{-1}$ of $\beta-\mathrm{Lg}$ microstructures, without quercetin, reduced the cell viability to $73.1 \%$, which demonstrated an adverse effect comparing to the control group $(p \leq 0.05)$. Martirosyan, Grintzalis, Polet, Laloux, and Schneider (2016) reported that silver nanoparticles (particle size $<20 \mathrm{~nm}$ ) reduced the Caco-2 cell viability, promoting the generation of ROS and reactive nitrogen species (RSN). Nevertheless, $50 \mu \mathrm{mol} \mathrm{L}{ }^{-1}$ of quercetin was able to protect cells against oxidative stress and/or inflammatory activities. Due to quercetin hydrophobic nature, absolute ethanol is often used to previously dissolve it (Al-Shabib et al., 2019). Then, a determined amount of quercetin stock solution was used to form $\beta-\mathrm{Lg}$ / quercetin microstructures. However, the organic solvent concentration used and cell exposure time could cause a toxic effect on Caco-2 cells (Tseng et al., 2006). Fig. 1B shows that ethanol at all concentrations tested (ethanol at equivalent concentration ranging of 0.128 to $40 \times 10^{-3} \mathrm{mg} \mathrm{mL}^{-1}$ of quercetin) did not produced cytotoxicity to the cells compared to the control group $(p>0.05)$. From Fig. 1B, cell viability above $100 \%$ was observed for free quercetin in all concentrations tested. Works reported in literature shows that cytotoxicity is narrowly associated with the oxidative stress in cells (Wang et al., 2014a) and as quercetin and its cellular metabolites have antioxidant properties, this compound is able to promote ROS scavenging due to cellular stress (Gonzales et al., 2016). Similar behaviour for other hydrophobic bioactive compound were reported by Le Maux, Giblin, Croguennec, Bouhallab, and Brodkorb (2012). These authors investigated the in vitro cytotoxicity on intestinal epithelial cells of $\beta$ - $\mathrm{Lg}$ as a vehicle of linoleate. They demonstrated an enhanced cell viability compared to the control group at low free bioactive compound concentrations (ranging from 5 to $25 \mu \mathrm{mol} \mathrm{L}{ }^{-1}$ ).

\subsection{Evaluation of $\beta$ - $L g$ micro- and nanostructures responsiveness along in vitro digestion process}

In order to evaluate the structural properties of $\beta-\mathrm{Lg}$ micro- and nanostructures during in vitro digestion, initial samples (i.e., before in vitro digestion) and samples collected in each digestion phase (i.e., oral, gastric and intestinal) were analysed in terms of particle size, PDI and surface charge by DLS (Table 2).

$\beta$-Lg microstructures' initial samples exhibited an average particle size ranging from $205.3 \pm 3.8$ to $235.7 \pm 7.8 \mathrm{~nm}$. whereas $\beta$ - $\mathrm{Lg}$ nanostructures initial samples showed average particle sizes between $58.0 \pm 1.7$ and $79.4 \pm 2.2 \mathrm{~nm}$ (Table 2). PDI values demonstrated that these structures were homogenous with a narrow size distribution (PDI < 0.25).

After mimicking the mouth digestion phase, $\beta$-Lg micro- and 
Table 2

Particle size, polydispersity index (PDI) and surface charge (S) of $\beta$-Lg micro- and nanostructures in each in vitro digestion phase.

\begin{tabular}{|c|c|c|c|c|}
\hline Structure & In vitro digestion phase & Particle size (nm) & PDI & $\mathrm{S}(\mathrm{mV})$ \\
\hline \multirow[t]{4}{*}{$\beta$-Lg micro } & Initial & $235.7 \pm 7.8^{\mathrm{a}}$ & $0.14 \pm 0.06^{\mathrm{a}}$ & $-19.7 \pm 2.1^{\mathrm{a}}$ \\
\hline & Oral & $226.0 \pm 8.6^{\mathrm{a}}$ & $0.20 \pm 0.03^{\mathrm{a}}$ & $-21.6 \pm 0.8^{\mathrm{a}}$ \\
\hline & Gastric & $3853.7 \pm 509.7^{\mathrm{b}}$ & $0.34 \pm 0.14^{\mathrm{ab}}$ & $1.0 \pm 0.2^{\mathrm{b}}$ \\
\hline & Intestinal & $529.1 \pm 44.0^{c}$ & $0.43 \pm 0.12^{\mathrm{b}}$ & $-24.3 \pm 0.6^{c}$ \\
\hline \multirow[t]{4}{*}{$\beta$ - $\mathrm{Lg} /$ riboflavin micro } & Initial & $205.3 \pm 3.8^{\mathrm{a}}$ & $0.23 \pm 0.03^{\mathrm{a}}$ & $-21.8 \pm 1.6^{\mathrm{a}}$ \\
\hline & Oral & $193.2 \pm 6.6^{\mathrm{a}}$ & $0.27 \pm 0.06^{\mathrm{a}}$ & $-23.8 \pm 1.4^{\mathrm{a}}$ \\
\hline & Gastric & $2655.7 \pm 362.8^{\mathrm{b}}$ & $0.53 \pm 0.08^{\mathrm{b}}$ & $11.1 \pm 0.4^{\mathrm{b}}$ \\
\hline & Intestinal & $547.1 \pm 40.7^{c}$ & $0.72 \pm 0.11^{\mathrm{c}}$ & $-23.2 \pm 0.5^{\mathrm{a}}$ \\
\hline \multirow[t]{4}{*}{$\beta$ - $\mathrm{Lg} /$ quercetin micro } & Initial & $224.4 \pm 6.4^{\mathrm{a}}$ & $0.18 \pm 0.03^{\mathrm{a}}$ & $-18.5 \pm 1.1^{\mathrm{a}}$ \\
\hline & Oral & $210.7 \pm 3.2^{\mathrm{a}}$ & $0.17 \pm 0.03^{\mathrm{a}}$ & $-21.0 \pm 1.1^{\mathrm{b}}$ \\
\hline & Gastric & $3136.9 \pm 220.1^{\mathrm{b}}$ & $0.69 \pm 0.16^{\mathrm{b}}$ & $2.0 \pm 0.4^{\mathrm{c}}$ \\
\hline & Intestinal & $538.6 \pm 30.8^{c}$ & $0.46 \pm 0.15^{\mathrm{c}}$ & $-21.4 \pm 0.6^{b}$ \\
\hline \multirow[t]{4}{*}{$\beta$-Lg nano } & Initial & $58.0 \pm 1.7^{\mathrm{a}}$ & $0.24 \pm 0.01^{\mathrm{a}}$ & $-16.8 \pm 1.0^{\mathrm{a}}$ \\
\hline & Oral & $66.6 \pm 2.8^{\mathrm{a}}$ & $0.37 \pm 0.02^{\mathrm{a}}$ & $-16.9 \pm 2.2^{\mathrm{a}}$ \\
\hline & Gastric & $1291.7 \pm 136.1^{\mathrm{b}}$ & $0.78 \pm 0.09^{\mathrm{b}}$ & $-1.5 \pm 0.3^{\mathrm{b}}$ \\
\hline & Intestinal & $582.4 \pm 39.9^{c}$ & $0.63 \pm 0.12^{\mathrm{c}}$ & $-22.6 \pm 0.9^{\mathrm{c}}$ \\
\hline \multirow[t]{4}{*}{$\beta$ - $\mathrm{Lg} /$ riboflavin nano } & Initial & $79.4 \pm 2.2^{\mathrm{a}}$ & $0.23 \pm 0.01^{\mathrm{a}}$ & $-16.5 \pm 0.3^{\mathrm{a}}$ \\
\hline & Oral & $79.5 \pm 2.7^{\mathrm{a}}$ & $0.25 \pm 0.01^{\mathrm{a}}$ & $-16.2 \pm 2.2^{\mathrm{a}}$ \\
\hline & Gastric & $4017.5 \pm 497.6^{\mathrm{b}}$ & $0.97 \pm 0.05^{\mathrm{b}}$ & $0.9 \pm 0.5^{\mathrm{b}}$ \\
\hline & Intestinal & $600.8 \pm 44.8^{c}$ & $0.66 \pm 0.06^{c}$ & $-24.3 \pm 0.6^{c}$ \\
\hline
\end{tabular}

a,b,c Different superscript letters indicate statistical difference in the same column for the same $\beta$-Lg structure between in vitro digestion phase mean values $(p \leq 0.05)$.

nanostructures size and PDI values remained similar to the values of initial samples $(p>0.05)$, indicating that $\beta$ - Lg structures were stable and maintained the initial characteristics under simulated oral phase with salivary fluids. The surface charge values suggested that electrostatic repulsion among the particles was sufficiently high enough to prevent aggregation. Taking in consideration the $\beta$ - $\mathrm{Lg}$ micro- and nanostructures as a potential oral delivery system, it is crucial to guarantee the protein structural properties until reaching the intestine (McClements, 2015).

After $\beta$-Lg micro- and nanostructures pass from the simulated oral to gastric phase (Table 2), an increase of particles' size was observed $(p \leq 0.05)$, suggesting that $\beta$-Lg structures at simulated gastric phase tend to agglomerate. These changes were accompanied by $\beta$-Lg structures instability, due to surface charge close to $0 \mathrm{mV}$, and heterogeneity, characterized by high PDI values ( $>0.34$ ) (Table 2). Indeed, the stomach environment is characterized by high acidity (i.e., $\mathrm{pH}$ value ranging from 1 to 3 ) and ionic strength (values around $100 \mathrm{mmol} \mathrm{L}^{-1}$ ) (Gonçalves et al., 2018). Considering that $\beta$-Lg micro- and nanostructures samples were initially at $\mathrm{pH} 6$ and their isoelectric point (pI) is near $\mathrm{pH} 4.8$, this could explain the results obtained in the gastric phase. The transition to gastric phase might promote changes in the interfacial composition leading to $\beta$ - $\mathrm{Lg}$ micro- and nanostructures aggregation. Madalena et al. (2016) described that $\beta-\mathrm{Lg} /$ riboflavin nanostructures particle size increased (from $232 \pm 21 \mathrm{~nm}$ to $329 \pm 23 \mathrm{~nm}$ ) after simulated gastric phase. The presence of intact $\beta$ - $\mathrm{Lg}$ structure in the stomach was depicted by Li, Cui, Ngadi, and Ma (2015). These authors performed an in vitro gastrointestinal digestion of $\beta$ - $\mathrm{Lg} /$ curcumin complex in simulated gastric fluid (SGF). The authors monitored the protein behaviour using SDS-PAGE and reported that the $\beta$-Lg band did not exhibit any reduction intensity in SGF after $90 \mathrm{~min}$ of digestion.

Results from the intestinal phase showed that surface charge of $\beta-\mathrm{Lg}$ micro- and nanostructures decreased to approximately $-22 \mathrm{mV}$ (Table 2), which were very similar to surface charge values of the $\beta$-Lg structure samples before in vitro digestion. This behaviour can be attributed to $\mathrm{pH}$ changing to 7 in intestinal phase and/or due adsorption of bile salts and electrolytes on sample surface (Hur, Decker, \& McClements, 2009; Pinheiro et al., 2013). Comparing to gastric phase digestion, it was observed a decrease of $\beta$-Lg micro- and nanostructures' particle sizes $(p \leq 0.05)$ in simulated intestinal phase; however, samples remained heterogeneous (PDI $>0.72$ ). These large particles sizes were due to precipitates formed during in vitro digestion. These precipitates production could be due to aggregation or flocculation provoked by digestive enzymes action or to changes in $\mathrm{pH}$ and ionic strength (Bourbon, Pinheiro, Cerqueira, \& Vicente, 2016; Pinheiro et al., 2013).

$\beta-\mathrm{Lg}$ micro- and nanostructures with and without a bioactive model compounds associated revealed similar behaviour for particle size, PDI and surface charge. The structural properties of $\beta$ - $\mathrm{Lg}$ micro- and nanostructures, during in vitro digestion process, were further characterized by native-PAGE and primary amine groups determination.

\subsection{1. $\beta$ - $\mathrm{Lg}$ micro- and nanostructures hydrolysis degree during in vitro digestion}

In order to predict the extent of $\beta-\mathrm{Lg}$ micro- and nanostructures hydrolysis during in vitro digestion, the TNBSA assay was performed to determine the number of peptide bonds cleaved (Fig. 2).

The TNBSA method determines the amount of primary amine molecules in the system (Spellman, McEvoy, O'Cuinn, \& FitzGerald, 2003). As the peptide bonds of $\beta-\mathrm{Lg}$ structures were cleaving during in vitro digestion, the number of free amino groups increased and consequently, the hydrolysis degree $(H D)$ increased.

The TNBSA results (Fig. 2) revealed that $H D$ of the initial samples (i.e., before in vitro digestion) and of the samples under simulated oral phase were maintained at values lower than $8.3 \%$. In both conditions, no statically significant differences $(p>0.05)$ were observed, independently of $\beta-\mathrm{Lg}$ structures studied. Additionally, the $H D$ profile observed for $\beta$ - $\mathrm{Lg}$ micro- and nanostructures in initial and oral phases was very similar to the ones observed to $\beta$ - $\mathrm{Lg}$ micro- and nanostructures with associated bioactive compounds. This behaviour was consistent with DLS data (Table 2), which showed that particle size, PDI and surface charge were maintained in initial and oral phases.

Subsequently, after $2 \mathrm{~h}$ under gastric phase, it was obtained a slight enhance of $\beta$ - $\mathrm{Lg}$ structures $H D$ to a maximum of $19.5 \%(p \leq 0.05)$. Generally, food proteins are usually hydrolysed in the stomach environment (Zhang \& Vardhanabhuti, 2014). Bourbon et al. (2018) evaluated both lactoferrin (Lf) and glycomacropeptide (GMP) nanohydrogels hydrolysis using an in vitro dynamic GI model. These authors observed that at least $45 \%$ of Lf and $70 \%$ of GMP remain undigested after simulated gastric phase. Our results demonstrated that $80.5 \%$ of $\beta$ - $\mathrm{Lg}$ micro- and nanostructures remained almost intact. $\beta$ - Lg is highly resistant to proteolytic enzymes and $\mathrm{pH}$ conditions of the stomach due to its stable globular tertiary structure at low $\mathrm{pH}$ (i.e., $\mathrm{pH}<3$ ) (Ramos 


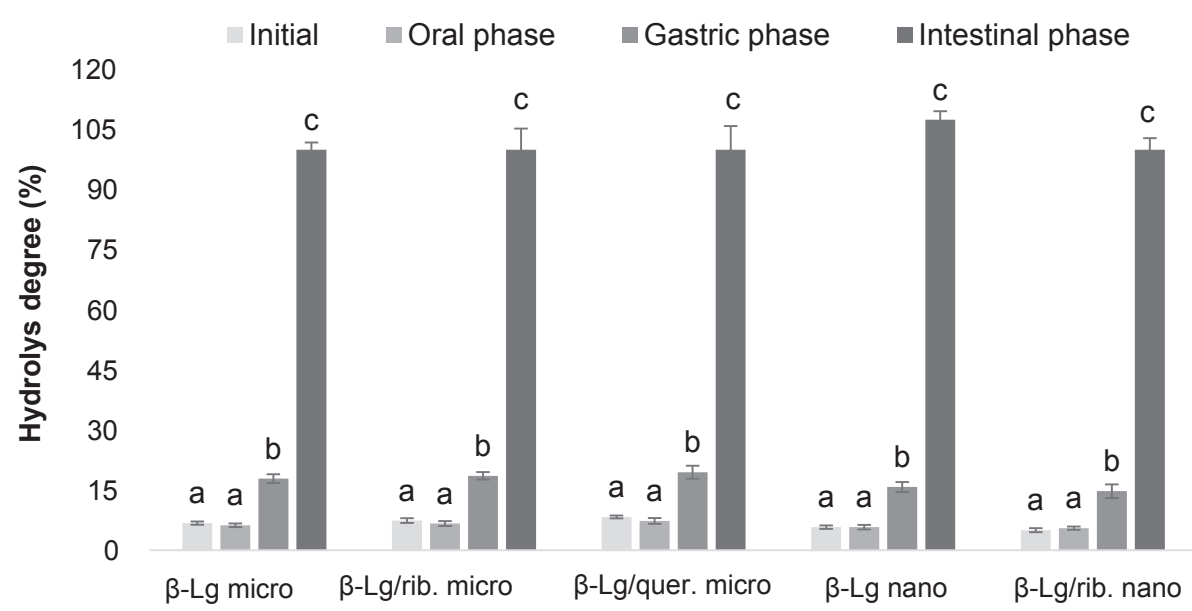

Fig. 2. Hydrolysis degree (\%) of $\beta \mathrm{Lg}$-micro and nanostructures with (or without) bioactive riboflavin (rib.) and quercetin (quer.) model compounds during in vitro digestion. ${ }^{\mathrm{a}, \mathrm{b}, \mathrm{c}}$ Small superscript letters in each column indicate statistical difference between means $(p \leq 0.05)$ for the same $\beta$-Lg structure.

et al., 2017). Pepsin is the major enzyme present in the gastric fluid and it has been reported that this enzyme has broad specificity with a preference for hydrophobic residues (Luo et al., 2015; Zhang \& Vardhanabhuti, 2014). Nonetheless, the highly hydrophobic $\beta$-barrel present inside the $\beta$-Lg structure hampers pepsin to access target peptide bonds (Bateman, Ye, \& Singh, 2010). These features are essential to maintain the protein stability until reaching the delivery target (Madalena et al., 2016).

After $\beta$-Lg micro- and nanostructures having been exposed to simulated intestinal conditions, the $H D$ reached $100 \%$ (Fig. 2), indicating a complete hydrolysis of the $\beta$-Lg structures. This result can be attributed to the proteolytic action of pancreatin, which digested $\beta$ - Lg microand nanostructures into smaller peptides (Mantovani, Pinheiro, Vicente, \& Cunha, 2017). These results are in agreement with others authors. Guo, Harris, Kaur, Pastrana, and Jauregi (2017) produced $\beta$-Lg nanoparticles for caffeine encapsulation and evaluated their behaviour upon in vitro digestion. The authors observed that caffeine remained entrapped in $\beta$ - $\mathrm{Lg}$ nanoparticles under the harsh stomach environment. However, a total release of the bioactive compound was achieved in intestinal conditions. Mandalari et al. (2009) proposed a work on a $\beta$-Lg in vitro digestion under simulated human gastric and duodenal conditions focused on the digestibility of protein. They reported that $\beta$ - $\mathrm{Lg}$ resists to physiological gastric digestion, being susceptible to degradation during duodenal digestion. Another interesting approach based on in vivo studies using force-fed rats was assessed by Diarrassouba et al. (2015) to enhance the bioavailability of vitamin $D_{3}$ associated with $\beta$ $\mathrm{Lg}$ nanoparticles. The authors demonstrated that $\beta$ - Lg nanoparticles were degraded and the bioactive compound released in the rat intestine.

To further explore the $\beta$ - $\mathrm{Lg}$ micro- and nanostructures hydrolysis, a native-PAGE electrophoresis was carried out.

\subsubsection{Native polyacrylamide gel electrophoresis (Native-PAGE)}

Native-PAGE electrophoresis is a complementary technique used to provide new insights on $\beta$ - $\mathrm{Lg}$ structures hydrolysis during in vitro digestion. Fig. 3 shows Native-PAGE series with sample band patterns, which allowed a better elucidation on the $\beta$ - $\mathrm{Lg}$ structures hydrolysis as function of the different in vitro digestion phases.

Gel electrophoresis is a technique for separation and analysis of macromolecules (e.g., proteins) and their fragments according to their molecular weight $\left(\boldsymbol{M}_{\boldsymbol{w}}\right)$ (Arndt, Koristka, Bartsch, \& Bachmann, 2012). Since pancreatin and pepsin are digestive enzymes (i.e., proteins) (Sullivan, Pangloli, \& Dia, 2018) used during in vitro digestion it was crucial to identify their $M_{w}$, as control samples. Native-PAGE results in Fig. 3A showed an in vitro digestion without samples (lane 1), pancreatin (lane 2) and pepsin (lane 3) profiles. Pancreatin is a mixture of several enzymes, for instance trypsin, amylase and lipase, secreted by the exocrine cells of pigs pancreas (Picariello et al., 2015). Pancreatin sample (lane 2) showed $M_{w}$ bands corresponding to trypsin $\left(M_{w}=20 \mathrm{kDa}\right)$, amylase $\left(M_{w}=45 \mathrm{kDa}\right)$ and lipase $\left(M_{w}=38 \mathrm{kDa}\right)$ (Shen, Liu, Lee, \& Chen, 2013). Moreover, pepsin (lane 3) was characterized by the presence of a single band with $M_{w}$ of $30 \mathrm{kDa}$. These results are in agreement with Peram, Loveday, Ye, and Singh (2013) results. These authors evaluated heat-induced $\beta$-Lg aggregates upon in vitro gastric digestion by native-PAGE electrophoresis and they obtained a $M_{w}=37 \mathrm{kDa}$ for pepsin. Thus, the bands identified in lanes 2 and 3 were presented in lane 1 , which correspond to the final sample taken from the in vitro digestion process.

$\beta-\mathrm{Lg}$ structures (with or without bioactive compounds) before in vitro digestion revealed similar electrophoretic profiles, showing the major $M_{w}$ band with values ranging from 15 to $20 \mathrm{kDa}$ (Fig. 3B $-\mathrm{F}$, lane 4). This band was attributed to $\beta$ - $\mathrm{Lg}$ because its $M_{w}$ is $18.4 \mathrm{kDa}$ (Zagury, Kazir, \& Livney, 2019). It was also observed the presence of a high $M_{w}$ band which could be related to protein aggregates formed during gelation treatment. These results were consistent with those reported elsewhere (Madalena et al., 2016; Rodrigues et al., 2015).

The electrophoretic profile of $\beta$ - $\mathrm{Lg}$ micro- and nanostructures upon oral phase and gastric phase showed two predominant bands with $M_{w}$ ranging from 15 to $20 \mathrm{kDa}$ (Fig. 3B-E, lanes 5 and 6). These results suggested that $\beta-\mathrm{Lg}$ micro- and nano-structures remained almost intact until the gastric phase - in agreement with the results obtained in TNBSA test. Moreover, the band corresponding to the $\beta-\mathrm{Lg}$ $\left(M_{w}=18 \mathrm{kDa}\right)$ was not detected in $\beta-\mathrm{Lg} /$ riboflavin nanostructures' samples after gastric phase (Fig. 3F, lane 6). Nevertheless, Madalena et al. (2016) studied $\beta$-Lg/riboflavin nanostructures throughout digestion, simulating the physiological conditions in the stomach and small intestine using an in vitro static GI system. The authors performed a native-PAGE electrophoresis for each in vitro digestion phase and obtained a $M_{w}$ band corresponding to $\beta$ - Lg after being submitted to gastric conditions. Taking into consideration the results obtained, including $H D$ data of $\beta-\mathrm{Lg} /$ riboflavin nanostructures, it can be suggested that $\beta-\mathrm{Lg}$ micro- and nanostructures are highly resistant to stomach environment conditions.

Similar electrophoresis profiles were observed comparing $\beta$-Lg micro- and nanostructures upon passage by the intestinal phase (Fig. 3B-F, lane 7). The band attributed to $\beta$ - $\mathrm{Lg}$ with $M_{w}$ ranging from 15 to $20 \mathrm{kDa}$ was not observed, suggesting the $\beta$ - Lg micro- and nanostructures degradation, which is in accordance with protein hydrolysis data of intestinal phase samples (Fig. 2). Despite the resistance of $\beta$-Lg, it was more susceptible to pancreatin degradation (Lassé et al., 2016). $\beta$-Lg degradation under intestinal conditions was also reported by Zagury et al. (2019) who conducted a study with $\beta$-Lg system to 
A

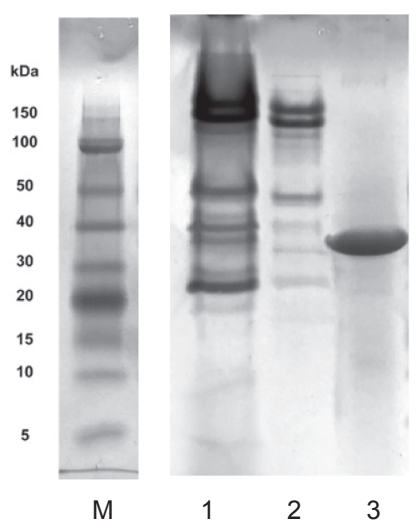

C



E

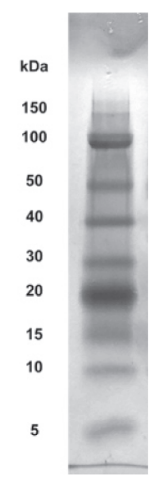

M



$\begin{array}{llll}4 & 5 & 6 & 7\end{array}$

B

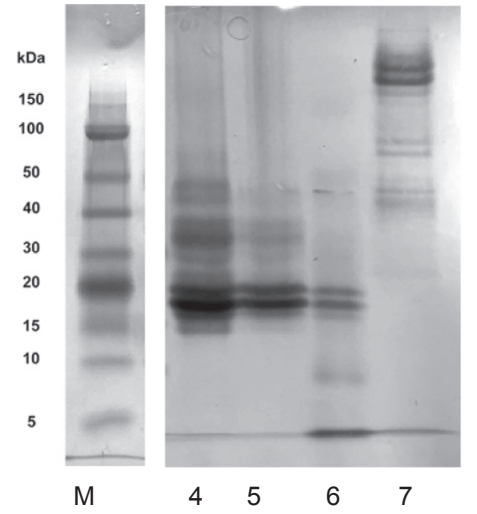

D

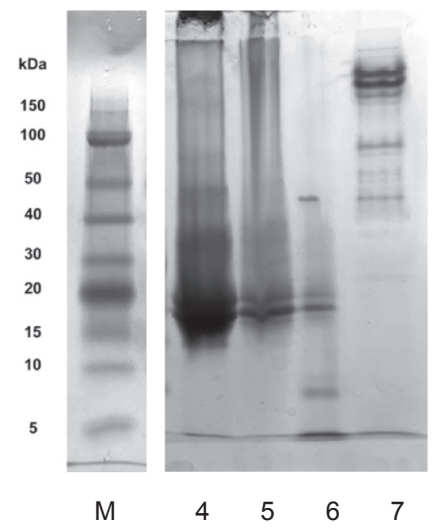

$\mathbf{F}$

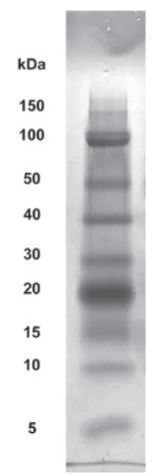

M

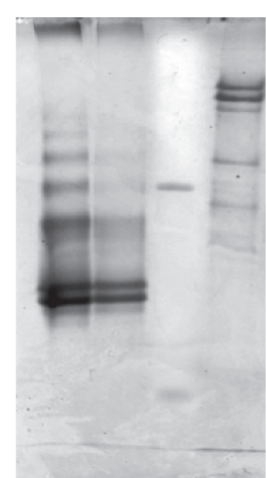

$\begin{array}{llll}4 & 5 & 6 & 7\end{array}$

Fig. 3. Native-PAGE of in vitro digestion samples: control (A); $\beta$-Lg microstructures (B); $\beta$ - $\mathrm{Lg}$ microstructures with riboflavin (C); $\beta$ - $\mathrm{Lg}$ microstructures with quercetin (D); $\beta$-Lg nanostructures (E); and $\beta$ - $\mathrm{Lg}$ nanostructures with riboflavin (F). The lanes represent: commercial molecular weight marker (M) intestinal phase of in vitro digestion without sample (1); pancreatin from porcine pancreas (2); pepsin from porcine gastric mucous (3); initial $\beta$-Lg structures (before in vitro digestion) (4); oral phase (5); gastric phase (6) and intestinal phase (7).

enhance the in vitro bioaccesibility of (-)-epigallocatechin-3-gallate. For this purpose, the authors performed a simulated GI digestion of the $\beta$ $\mathrm{Lg} /(-)$-epigallocatechin-3-gallate system and obtained $\beta$-Lg resistance in simulate gastric conditions and a complete degradation under intestinal environment. Diarrassouba et al. (2013b) studied the pH-stability of the $\beta$ - $\mathrm{Lg} /$ vitamin $\mathrm{D}_{3}$ complex to evaluate the potential impact on the stability of such structures through the GI tract. The authors concluded that $\beta-\mathrm{Lg} / \mathrm{D}_{3}$ complex remained stable under acidic ( $\mathrm{pH}$ ranging from 3.0 to 4.0 ) and alkaline (pH ranging from 6.8 to 8.0) environments, suggesting that this complex could be $\mathrm{pH}$ stable along the digestion process.

\subsection{Bioactive model compounds behaviour under gastrointestinal environmental conditions}

Throughout in vitro GI digestion, $\beta$ - $\mathrm{Lg}$ micro- and nanostructures were subjected to several conditions, such as $\mathrm{pH}$ changes and enzymatic action. These factors could affect the capacity of such structures to protect bioactive compounds. Therefore, the amounts of intact riboflavin and quercetin in oral, gastric and intestinal phases were assessed (Fig. 4).

Fig. 4A shows the intact riboflavin in free form (\%) during in vitro digestion. Free riboflavin (Fig. 4A) results showed that only $28.7 \pm 0.4$ $\%$ of their initial concentration (i.e., $0.105 \mathrm{mg} \mathrm{mL}^{-1}$ ) reached the 

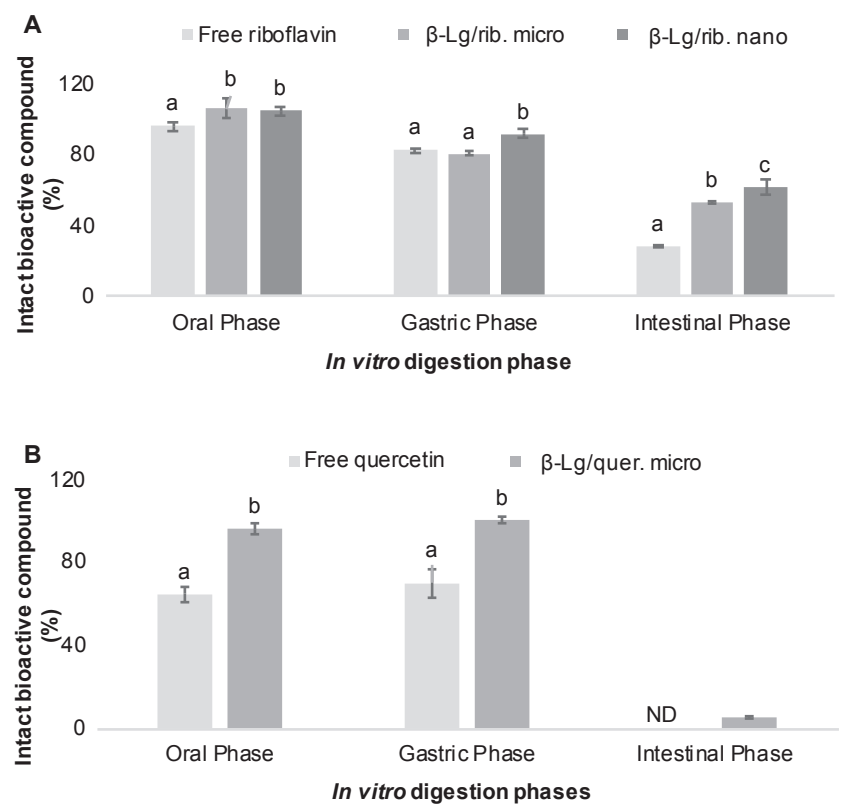

Fig. 4. Intact (\%) free riboflavin, $\beta-\mathrm{Lg} /$ riboflavin micro- and nanostructures A) and free quercetin and $\beta-\mathrm{Lg}$ /quercetin microstructures $\mathrm{B}$ ) in oral, gastric and intestinal phases during in vitro digestion. Results were present as mean \pm standard deviation. ${ }^{\text {a,b,c }}$ Different small letter superscripts in the same in vitro digestion phase correspond to statistically significantly differences ( $p \leq 0.05$ ). ND means that the concentration of quercetin was Not Detected.

intestinal phase; thus, it is crucial to use $\beta$ - $\mathrm{Lg}$ structures to protect them from chemical and enzymatic degradation.

On the first phase of digestion (i.e., oral phase with simulated salivary fluid), it was observed a decrease $(p \leq 0.05)$ of free riboflavin concentration of ca. $3 \%$ (to $96.6 \pm 2.0 \%$ ) compared with $\beta-\mathrm{Lg} / \mathrm{ri}$ boflavin micro- $(106.0 \pm 5.5 \%)$ and nano $(104.9 \pm 2.6 \%)$ structures. The harmonized INFOGEST in vitro model mimics the oral phase, which is constituted by a neutral environment (i.e., pH 7) and an electrolyte solution (SSF) (Minekus et al., 2014). The presence of ions in the SSF did not affect the $\beta$ - $\mathrm{Lg}$ micro- and nanostructure properties (Table 2), which might delay the riboflavin degradation in the oral phase, when compared to the free form.

In the gastric phase (Fig. 4A), $81.2 \pm 1.7 \%$ of riboflavin from $\beta$ $\mathrm{Lg} /$ riboflavin microstructure samples were intact. This result was similar $(p>0.05)$ to that obtained for free riboflavin. However, the percentage of intact riboflavin from $\beta-\mathrm{Lg} /$ riboflavin nanostructures was significantly different $(p \leq 0.05)$ from those obtained for riboflavin in free form or for $\beta-\mathrm{Lg} /$ riboflavin microstructures. This behaviour suggests that $\beta$-Lg nanostructures were able to better protect riboflavin from degradation at gastric phase than $\beta$-Lg microstructures. Intestinal phase results (Fig. 4A) shown that $\beta$-Lg microstructures were able to retain $53.2 \pm 0.9 \%$ of intact riboflavin until absorption, whereas $\beta$ - $\mathrm{Lg}$ nanostructures maintained $61.7 \pm 4.1 \%$ of intact riboflavin $(p \leq 0.05)$. The information obtained in this study was consistent with results observed by Maltais, Remondetto, and Subirade (2010). The authors investigated a soy protein filamentous hydrogel for riboflavin release under simulated GI conditions. They observed in simulated gastric fluid with pepsin, that $13 \%$ of total riboflavin was released from hydrogel. It was argued that the low riboflavin release in gastric conditions was due to the soy hydrogel resistance to pepsin. The pepsin resistance was attributed to a low amount of hydrophobic aromatic amino acids available in soy protein hydrogel, which are the preferential cleavage sites of pepsin in proteins. Moreover, the pancreatin in intestinal phase led to the thorough soy protein filamentous hydrogels degradation and $100 \%$ release of initial riboflavin concentration used.
Quercetin content in each in vitro digestion phase was also studied (Fig. 4B). Free quercetin started to be degraded after exposure to simulated oral phase conditions, being the level of intact quercetin of $65.0 \pm 3.5 \%$ in relation to the initial quercetin concentration (i.e., $0.8 \mathrm{mg} \mathrm{mL}^{-1}$ ). The content of free quercetin content was maintained in the gastric phase, being, however, not detected in the intestinal phase (Fig. 4B). These results demonstrated that quercetin needs to be protected from physiological GI tract conditions, since this hydrophobic bioactive compound has a poor solubility, rapid metabolism and low absorption (Chen, Zou, Liu, \& McClements, 2016). Quercetin has poor water solubility (Wang et al., 2014b), and requires prior solubilization in an organic solvent, in this case, ethanol. When this ethanolic solution is added in the aqueous system, large precipitates were formed, displaying an atypical needle-like morphology, which is extremely unstable (Patel, Heussen, Hazekamp, Drost, \& Velikov, 2012). Moreover, quercetin also has a low solubility in simulated gastric $\left(5.5 \mu \mathrm{g} \mathrm{mL}{ }^{-1}\right)$ and intestinal (28.9 $\mu \mathrm{g} \mathrm{mL}^{-1}$ ) fluids (Gao et al., 2009), which increase the formation of precipitates when quercetin is present in its free form. When quercetin is associated with $\beta$ - $\mathrm{Lg}$ microstructures (Fig. 4B), it was observed an increase of the content of intact quercetin along the various phases of in vitro digestion $(p \leq 0.05)$. The content of intact quercetin increased in oral and gastric phases being $96.2 \pm 2.5 \%$ and $100.5 \pm 1.5 \%$, respectively, and decreased in the intestinal phase to $5.3 \pm 0.5 \%$. This behaviour may be attributed to the fact that quercetin molecules were protected by the $\beta$ - $\mathrm{Lg}$ microstructures from the surrounding aqueous phase (Chen et al., 2018), avoiding their degradation. Fang et al. (2011) developed bovine serum album nanoparticles to encapsulate quercetin and reported that the system could maintain quercetin bioactive properties under both neutral and acidic environments.

\subsubsection{Bioactive model compounds bioaccessibility and bioavailability}

In the reports found in the literature regarding the food applications, studies about the determination of bioaccessibility and bioavailability of bioactive compounds are still limited. In this sense, the evaluation of riboflavin and quercetin bioaccessibility and bioavailability potential was conducted to fill this gap (Fig. 5).

Bioaccessibility is related with the fraction of bioactive compound released from the structure and potentially available for absorption (Gonçalves et al., 2018). The riboflavin bioaccessibility results (Fig. 5A) revealed that $100 \%$ of riboflavin in free form and $\beta-\mathrm{Lg} /$ riboflavin micro- and nanostructures that reach the intestinal phase can be potentially absorbed. This can be due to the water solubility properties of riboflavin that may facilitate a higher passage through the various simulated GI phases. Regarding quercetin bioaccessibility results (Fig. 5B), this bioactive compound in free form was not capable to reach to intestinal phase and be bioaccessible, which may be attributed to the low solubility of quercetin in simulated intestinal fluid (Chen et al., 2018).

The bioaccessibility of quercetin in free form in bulk water was reported to be low $\left(<5 \%\right.$ ) when tested at 0.1 and $0.5 \mathrm{mg} \mathrm{mL}^{-1}$ (Pool, Mendoza, Xiao, \& McClements, 2013). Nevertheless, $\beta$-Lg microstructures enhanced quercetin bioaccessibility (Fig. 5B) to $11.8 \pm 1.0$ $\%(p \leq 0.05)$, which is in agreement with previous studies on protein as a promising vehicle for hydrophobic compounds (Chen, Li, \& Tang, 2015). This result may be attributed to the $\beta$ - Lg microstructures capacity to protect quercetin from the aqueous environment. Also, this suggests that after hydrolysis of $\beta$ - Lg microstructures under simulated intestinal phase conditions, the presence of digestion products (i.e., mixed micelles) formed by bile salts and bile acids allowed solubilizing free fatty acids, monoacylglycerols and some bioactive compounds (Pinheiro, Coimbra, \& Vicente, 2016).

According to the literature, the term "bioavailability" is related to the amount of the compound ingested, which is absorbed and reaches the systemic circulation to exert its physiological functions (Gonçalves et al., 2018). In this regard, since our research did not perform 




B 160

$$
\text { ND Free quer. } \quad \beta \text {-Lg/quer. micro }
$$

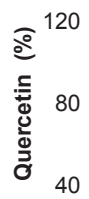

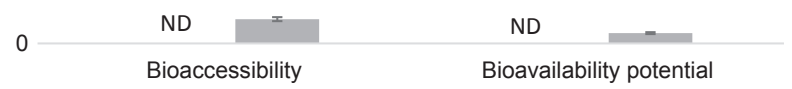

Fig. 5. Bioaccessibility and bioavailability potential of $\beta-\mathrm{Lg} /$ riboflavin microand nanostructures A) and $\beta-\mathrm{Lg} /$ quercetin microstructures B). ${ }^{\text {a,b,c }}$ Samples in the same parameter designated with different letters superscripts are significantly different $(p \leq 0.05)$. ND means that the concentration of quercetin was Not Detected.

riboflavin and quercetin absorption studies (i.e., transport using Caco-2 cell monolayer), the term "bioavailability potential" was used. Comparing with the riboflavin in free form, $\beta$-Lg micro- and nanostructures were capable to enhance riboflavin bioavailability potential $(p \leq 0.05)$ (Fig. 5A). Bourbon et al. (2018) observed a similar behaviour when using a dynamic in vitro GI model to determine the bioavailable fraction of caffeine (as hydrophilic model compound) using Lf-GMP nanohydrogels with chitosan coating as the encapsulation matrix. The authors obtained a caffeine bioavailability of $63.1 \pm 0.2 \%$ when caffeine was associated to nanohydrogels and of $59.2 \pm 2.1 \%$ when caffeine is present in its free form. Riboflavin bioavailability potential (Fig. 5A) significantly increased $(p \leq 0.05)$ when the particle size decreased, being $60.0 \pm 0.4 \%$ for $\beta$ - $L$ g micro-structures and $73.2 \pm 5.5 \%$ for $\beta$ $\mathrm{Lg}$ nanostructures. Indeed, the reduced size of $\beta-\mathrm{Lg}$ nanostructures may has higher potential to improve the solubility, and bioavailability potential, in preventing undesirable physical and chemical reactions, as well as in protecting bioactive compounds against degradation (Samadarsi \& Dutta, 2019).

As shown in Fig. 5B, $\beta$ - Lg/quercetin microstructures demonstrated a prominent enhancement of quercetin absorption, leading to an increase of bioavailability potential $5.0 \pm 0.5 \%$, when compared to quercetin in free form. Diarrassouba et al. (2015) evaluated $\beta$-Lg-based coagulum matrix as oral delivery system for of vitamin $D_{3}$ and obtained an enhanced bioactive compound bioavailability determined by rat plasma analysis.

After assessing the bioactive compounds concentration which reached intestinal phase (Fig. 4), bioaccessible and bioavailable potential fraction of model bioactive compounds (Fig. 5), it was possible to determine the effective riboflavin and quercetin concentrations that might be potentially absorbed. First, we considered our previous association efficiency ( $A E$ ) results (Simões, Abrunhosa, et al., 2020), where we evaluated the bioactive compound fraction successfully entrapped within structures. The initial riboflavin concentration used was $0.105 \mathrm{mg} \mathrm{mL}^{-1}$, which led to a maximum association efficiency $(A E)$ of $64.4 \%$ for both $\beta$-Lg micro- and nanostructures. After determining the hydrophilic bioactive compound concentration in intestinal phase and riboflavin bioaccessibility and bioavailability potential (Fig. 5A), $\beta-\mathrm{Lg} /$ riboflavin microstructures were able to maintain $21.6 \times 10^{-3} \mathrm{mg}$ $\mathrm{mL}^{-1}$ of riboflavin, while $\beta-\mathrm{Lg} /$ riboflavin nanostructures were capable to retain $31.0 \times 10^{-3} \mathrm{mg} \mathrm{mL} \mathrm{mL}^{-1}$ of riboflavin. Based on Caco- 2 cell viability results of $\beta-\mathrm{Lg} /$ riboflavin micro- and nanostructures, $21 \times 10^{-3} \mathrm{mg} \mathrm{mL}^{-1}$ of riboflavin was non-cytotoxic to Caco-2 cells. Thus, the riboflavin fraction that remained potentially bioavailable in this study indicated that $\beta$ - $\mathrm{Lg} /$ riboflavin micro- and nanostructures could be eventually cytotoxic to Caco- 2 cells. However, the potential bioavailability value was calculated based in an empirical model that do not consider an extensive bioactive compound metabolic conversion related with GI digestion. Overall, the bioavailability is influence by several physical and chemical characteristics, for instance, the concentration of bioactive compound that reached intestinal without chemical transformations; the bioactive compound fraction not metabolized by the gut and; the bioactive compound transport coefficient and permeability (Ting, Jiang, Ho, \& Huang, 2014). Therefore, bioavailability is a complex parameter and more studies would be needed to determined its real value.

Regarding quercetin, the initial concentration used was $0.08 \mathrm{mg} \mathrm{mL}^{-1}$ and $\beta$-Lg/quercetin microstructures revealed $98.0 \%$ of $A E$ (Simões, Abrunhosa, et al., 2020). Based on results presented in Fig. $5 \mathrm{~B}$, it was assessed that $\beta$ - $\mathrm{Lg}$ /quercetin micro-structures were able to maintain $0.46 \times 10^{-3} \mathrm{mg} \mathrm{mL}^{-1}$ quercetin potential bioavailable after simulated GI tract. Based on Caco- 2 cell viability results of $\beta-\mathrm{Lg} /$ quercetin microstructures, $16 \times 10^{-3} \mathrm{mg} \mathrm{mL}^{-1}$ quercetin maintained $100 \%$ of cell viability. Therefore, since this structure remained potential bioavailable at $0.35 \times 10^{-3} \mathrm{mg} \mathrm{mL}^{-1}$ of quercetin, this is an indication that the $\beta$ - $\mathrm{Lg}$ /quercetin microstructures produced could be used without potential risk to cells.

\section{Conclusions}

The cell viability assay reported herein have demonstrated that the concentration of $\beta$ - $\mathrm{Lg}$ /quercetin microstructures (i.e., before in vitro digestion) were non-toxic to Caco-2 cells.

In vitro GI digestion results demonstrated that $\beta$-Lg micro- and nanostructures were effective in protecting both hydrophilic and hydrophobic bioactive compounds during the gastric phase, thus releasing them in the desirable target site (i.e., intestine), where $\beta$-Lg structures were completely hydrolysed. Moreover, the in vitro digestion results indicated an improvement of both bioactive compounds fractions bioavailability potential on $\beta-\mathrm{Lg} /$ riboflavin micro- and nanostructures, and on $\beta-\mathrm{Lg} /$ quercetin microstructures when compared to the respective compound in its free form.

Our work results contributed to the improvement of the knowledge regarding the use of $\beta-\operatorname{Lg}$ micro- and nanostructures as an effective oral delivery system strategy to augment the hydrophilic and hydrophobic bioactive compounds' bioavailability potential. However, further studies will be needed to fully understand the behaviour of $\beta$ - Lg microand nanostructures during digestion for example, using a dynamic GI model that mimics the GI peristaltic movements. Also, it would be important to assess the permeability and absorption rates of both bioactive model compounds across Caco-2/HT-29 cells, once this other system allows simulating the production of mucus on the epithelium, thus mimicking more closely its properties.

\section{Acknowledgments}

Lívia de Souza Simões gratefully acknowledges her grant to CNPq (Conselho Nacional de Desenvolvimento Científico e Tecnológico, Brasil) from Brazil. The authors also would like to acknowledge Luís Abrunhosa, from Centre of Biological Engineering, for assistance in High Pressure Liquid Chromatography - Fluorescence detection. This study was supported by FCT under the scope of the strategic funding of UID/BIO/04469/2013 unit and COMPETE 2020 (POCI-01-0145FEDER-006684) and BioTecNorte operation (NORTE-01-0145-FEDER- 
000004) funded by the European Regional Development Fund under the scope of Norte2020 - Programa Operacional Regional do Norte. This study was also supported by FCT under the scope of the Project RECI/ BBB-EBI/0179/2012 (FCOMP-01-0124-FEDER-027462).

\section{References}

Al-Shabib, N. A., Khan, J. M., Malik, A., Sen, P., Alsenaidy, M. A., Husain, F. M., ... Shahzad, S. A. (2019). A quercetin-based flavanoid (rutin) reverses amyloid fibrillation in $\beta$-lactoglobulin at $\mathrm{pH} 2.0$ and $358 \mathrm{~K}$. Spectrochimica Acta Part A: Molecular and Biomolecular Spectroscopy, 214, 40-48. https://doi.org/10.1016/j.saa. 2019.02.004.

Arndt, C., Koristka, S., Bartsch, H., \& Bachmann, M. (2012). Native polyacrylamide gels. In B. T. Kurien, \& R. H. Scofield (Vol. Eds.), Protein Electrophoresis: Methods and Protocols, Methods in Molecular Biology: Vol. 869, (pp. 49-53). Springer. https://doi. org/10.1007/978-1-60327-375-6_23.

Bateman, L., Ye, A., \& Singh, H. (2010). In vitro digestion of $\beta$-lactoglobulin fibrils formed by heat treatment at low pH. Journal of Agricultural and Food Chemistry, 58(17), 9800-9808. https://doi.org/10.1021/jf101722t.

Benedetti, A., Alvaro, D., Bassotti, C., Gigliozzi, A., Ferretti, G., La Rosa, T., ... Jezequel, A. M. (1997). Cytotoxicity of bile salts against biliary epithelium: A study in isolated bile ductule fragments and isolated perfused rat liver. Hepatology, 26(1), 9-21. https:// doi.org/10.1002/hep.510260102.

Bourbon, A. I., Pinheiro, A. C., Cerqueira, M. A., \& Vicente, A. A. (2016). Influence of chitosan coating on protein-based nanohydrogels properties and in vitro gastric digestibility. Food Hydrocolloids, 60, 109-118. https://doi.org/10.1016/j.foodhyd. 2016.03.002.

Bourbon, A. I., Pinheiro, A. C., Cerqueira, M. A., \& Vicente, A. A. (2018). In vitro digestion of lactoferrin-glycomacropeptide nanohydrogels incorporating bioactive compounds: Effect of a chitosan coating. Food Hydrocolloids, 84(February), 267-275. https://doi. org/10.1016/j.foodhyd.2018.06.015.

Braz, L., Grenha, A., Ferreira, D., Rosa da Costa, A. M., Gamazo, C., \& Sarmento, B. (2017). Chitosan/sulfated locust bean gum nanoparticles: In vitro and in vivo evaluation towards an application in oral immunization. International Journal of Biological Macromolecules, 96, 786-797. https://doi.org/10.1016/j.ijbiomac.2016.12. 076.

Castillo, B., Mendez, J., Al-Azzam, W., Barletta, G., \& Griebenow, K. (2006). On the relationship between the activity and structure of PEG- $\alpha$-chymotrypsion conjugates in organic solvents. Biotechnology Bioengineering, 94(3), 565-574. https://doi.org/10. 1002/bit.

Chen, F. P., Li, B. S., \& Tang, C. H. (2015). Nanocomplexation between Curcumin and Soy Protein Isolate: Influence on Curcumin Stability/Bioaccessibility and In Vitro Protein Digestibility. Journal of Agricultural and Food Chemistry, 63(13), 3559-3569. https:// doi.org/10.1021/acs.jafc.5b00448.

Chen, X., McClements, D. J., Zhu, Y., Chen, Y., Zou, L., Liu, W., ... Liu, C. (2018). Enhancement of the solubility, stability and bioaccessibility of quercetin using protein-based excipient emulsions. Food Research International, 114(July), 30-37. https://doi.org/10.1016/j.foodres.2018.07.062

Chen, X., Zou, L., Liu, W., \& McClements, D. J. (2016). Potential of excipient emulsions for improving Quercetin Bioaccessibility and antioxidant activity: An In Vitro Study. Journal of Agricultural and Food Chemistry, 64(18), 3653-3660. https://doi.org/10. 1021/acs.jafc.6b01056.

Diarrassouba, F., Garrait, G., Remondetto, G., Alvarez, P., Beyssac, E., \& Subirade, M. (2015). Improved bioavailability of vitamin $D_{3}$ using a $\beta$-lactoglobulin-based coagulum. Food Chemistry, 172, 361-367. https://doi.org/10.1016/j.foodchem.2014.09. 054.

Diarrassouba, F., Liang, L., Remondetto, G., \& Subirade, M. (2013). Nanocomplex formation between riboflavin and $\beta$-lactoglobulin: Spectroscopic investigation and biological characterization. Food Research International, 52(2), 557-567. https://doi. org/10.1016/j.foodres.2013.03.025.

Diarrassouba, F., Remondetto, G., Liang, L., Garrait, G., Beyssac, E., \& Subirade, M. (2013). Effects of gastrointestinal $\mathrm{pH}$ conditions on the stability of the $\beta$-lactoglobulin/vitamin $\mathrm{D}_{3}$ complex and on the solubility of vitamin $\mathrm{D}_{3}$. Food Research International, 52(2), 515-521. https://doi.org/10.1016/j.foodres.2013.02.026.

Fang, R., Hao, R., Wu, X., Li, Q., Leng, X., \& Jing, H. (2011). Bovine serum albumin nanoparticle promotes the stability of quercetin in simulated intestinal fluid. Journal of Agricultural and Food Chemistry, 59(11), 6292-6298. https://doi.org/10.1021/ jf200718j.

Gao, Y., Wang, Y., Ma, Y., Yu, A., Cai, F., Shao, W., \& Zhai, G. (2009). Formulation optimization and in situ absorption in rat intestinal tract of quercetin-loaded microemulsion. Colloids and Surfaces B: Biointerfaces, 71(2), 306-314. https://doi.org/10. 1016/j.colsurfb.2009.03.005

Gonçalves, R. F. S., Martins, J. T., Duarte, C. M. M., Vicente, A. A., \& Pinheiro, A. C (2018). Advances in nutraceutical delivery systems: From formulation design for bioavailability enhancement to efficacy and safety evaluation. Trends in Food Science and Technology, 78(January), 270-291. https://doi.org/10.1016/j.tifs.2018.06.011.

Gonzales, G. B., Smagghe, G., Vissenaekens, H., Grootaert, C., Rajkovic, A., Van de Wiele, T., ... Van Camp, J. (2016). Quercetin mitigates valinomycin-induced cellular stress via stress-induced metabolism and cell uptake. Molecular Nutrition and Food Research, 60(5), 972-980. https://doi.org/10.1002/mnfr.201500999.

Guo, Y., Harris, P., Kaur, A., Pastrana, L., \& Jauregi, P. (2017). Characterisation of $\beta$ lactoglobulin nanoparticles and their binding to caffeine. Food Hydrocolloids, 71, 85-93. https://doi.org/10.1016/j.foodhyd.2017.04.027.

Ha, H., Kim, J. W., Lee, M., Jun, W., \& Lee, W. (2015). Cellular uptake and cytotoxicity of
$\beta$-Lactoglobulin nanoparticles: the effects of particle size and surface charge. Asian Australas. J. Anim. Sci., 28(3), 420-427. https://doi.org/10.5713/ajas.14.0761.

Hur, S. J., Decker, E. A., \& McClements, D. J. (2009). Influence of initial emulsifier type on microstructural changes occurring in emulsified lipids during in vitro digestion. Food Chemistry, 114(1), 253-262. https://doi.org/10.1016/j.foodchem.2008.09.069.

Komori, A., Inoue, N., Fujita, K., Kasajima, S., \& Horii, A. (2007). Measurement of Rutin and Quercetin in Tartary Buckwheat Flour by Ultraviolet-Induced Fluorescence. Proceedings of the 10th .... Retrieved from < http://citeseerx.ist.psu.edu/viewdoc/ download? doi $=10 \cdot 1 \cdot 1 \cdot 578 \cdot 2253 \&$ rep $=$ rep $1 \&$ type $=$ pdf $>$

Lassé, M., Ulluwishewa, D., Healy, J., Thompson, D., Miller, A., Roy, N., ... Gerrard, J. A. (2016). Evaluation of protease resistance and toxicity of amyloid-like food fibrils from whey, soy, kidney bean, and egg white. Food Chemistry, 192, 491-498. https:/ doi.org/10.1016/j.foodchem.2015.07.044.

Le Maux, S., Brodkorb, A., Croguennec, T., Hennessy, A. a, Bouhallab, S., \& Giblin, L. (2013). $\beta$-Lactoglobulin-linoleate complexes: In vitro digestion and the role of protein in fatty acid uptake. Journal of Dairy Science, 96(7), (pp. 4258-4268). https://doi. org/10.3168/jds.2013-6682.

Le Maux, S., Giblin, L., Croguennec, T., Bouhallab, S., \& Brodkorb, A. (2012). $\beta$ Lactoglobulin as a molecular carrier of linoleate: Characterization and effects on intestinal epithelial cells in vitro. Journal of Agricultural and Food Chemistry, 60(37), 9476-9483. https://doi.org/10.1021/jf3028396.

Li, M., Cui, J., Ngadi, M. O., \& Ma, Y. (2015). Absorption mechanism of whey-proteindelivered curcumin using Caco-2 cell monolayers. Food Chemistry, 180, 48-54. https://doi.org/10.1016/j.foodchem.2015.01.132.

Liu, W., Wang, J., McClements, D. J., \& Zou, L. (2018). Encapsulation of $\beta$-caroteneloaded oil droplets in caseinate/alginate microparticles: Enhancement of carotenoid stability and bioaccessibility. Journal of Functional Foods, 40(December 2017), 527-535. https://doi.org/10.1016/j.jff.2017.11.046.

Luo, Q., Boom, R. M., \& Janssen, A. E. M. (2015). Digestion of protein and protein gels in simulated gastric environment. LWT - Food Science and Technology, 63(1), 161-168. https://doi.org/10.1016/j.lwt.2015.03.087.

Madadlou, A., Floury, J., Pezennec, S., \& Dupont, D. (2018). Encapsulation of $\beta$-lactoglobulin within calcium carbonate microparticles and subsequent in situ fabrication of protein microparticles. Food Hydrocolloids, 84(March), 38-46. https://doi.org/10. 1016/j.foodhyd.2018.05.054.

Madalena, D. A., Ramos, Ó. L., Pereira, R. N., Bourbon, A. I., Pinheiro, A. C., Malcata, F. X., ... Vicente, A. A. (2016). In vitro digestion and stability assessment of $\beta$-lactoglobulin/riboflavin nanostructures. Food Hydrocolloids, 58, 89-97. https://doi.org/ 10.1016/j.foodhyd.2016.02.015.

Maltais, A., Remondetto, G. E., \& Subirade, M. (2010). Tabletted soy protein cold-set hydrogels as carriers of nutraceutical substances. Food Hydrocolloids, 24(5), 518-524. https://doi.org/10.1016/j.foodhyd.2009.11.016.

Mandalari, G., Adel-Patient, K., Barkholt, V., Baro, C., Bennett, L., Bublin, M., ... Mills, E. N. C. (2009). In vitro digestibility of $\beta$-casein and $\beta$-lactoglobulin under simulated human gastric and duodenal conditions: A multi-laboratory evaluation. Regulatory Toxicology and Pharmacology, 55(3), 372-381. https://doi.org/10.1016/j.yrtph.2009. 08.010.

Mantovani, R. A., Pinheiro, A. C., Vicente, A. A., \& Cunha, R. L. (2017). In vitro digestion of oil-in-water emulsions stabilized by whey protein nanofibrils. Food Research International, 99(June), 790-798. https://doi.org/10.1016/j.foodres.2017.06.049.

Martirosyan, A., Grintzalis, K., Polet, M., Laloux, L., \& Schneider, Y. J. (2016). Tuning the inflammatory response to silver nanoparticles via quercetin in Caco-2 (co-)cultures as model of the human intestinal mucosa. Toxicology Letters, 253, 36-45. https://doi. org/10.1016/j.toxlet.2016.04.018.

McClements, D. J. (2015). Encapsulation, protection, and release of hydrophilic active components: Potential and limitations of colloidal delivery systems. Advances in Colloid and Interface Science, 219, 27-53. https://doi.org/10.1016/j.cis.2015.02.002.

Minekus, M., Alminger, M., Alvito, P., Ballance, S., Bohn, T., Bourlieu, C., ... Brodkorb, A (2014). A standardised static in vitro digestion method suitable for food-an international consensus. Food and Function, 5(6), 1113-1124. https://doi.org/10.1039/ c3fo60702j.

O'Neill, G. J., Jacquier, J. C., Mukhopadhya, A., Egan, T., O'Sullivan, M., Sweeney, T., \& O'Riordan, E. D. (2015). In vitro and in vivo evaluation of whey protein hydrogels for oral delivery of riboflavin. Journal of Functional Foods, 19, 512-521. https://doi.org/ 10.1016/j.jff.2015.09.043.

Patel, A. R., Heussen, P. C. M., Hazekamp, J., Drost, E., \& Velikov, K. (2012). Quercetin loaded biopolymeric colloidal particles prepared by simultaneous precipitation of quercetin with hydrophobic protein in aqueous medium. Food Chemistry, 133(2), 423-429. https://doi.org/10.1016/j.foodchem.2012.01.054.

Peram, M. R., Loveday, S. M., Ye, A., \& Singh, H. (2013). In vitro gastric digestion of heatinduced aggregates of $\beta$-lactoglobulin. Journal of Dairy Science, 93, 63-74. https:// doi.org/10.3168/jds.2012-5896.

Picariello, G., Miralles, B., Mamone, G., Sánchez-Rivera, L., Recio, I., Addeo, F., \& Ferranti, P. (2015). Role of intestinal brush border peptidases in the simulated digestion of milk proteins. Molecular Nutrition and Food Research, 59(5), 948-956. https://doi.org/10.1002/mnfr.201400856.

Pinheiro, A. C., Coimbra, M. A., \& Vicente, A. A. (2016). In vitro behaviour of curcumin nanoemulsions stabilized by biopolymer emulsifiers - Effect of interfacial composition. Food Hydrocolloids, 52, 460-467. https://doi.org/10.1016/j.foodhyd.2015.07. 025 .

Pinheiro, A. C., Gonçalves, R. F. S., Madalena, D. A., \& Vicente, A. A. (2017). Towards the understanding of the behavior of bio-based nanostructures during in vitro digestion. Current Opinion in Food Science. https://doi.org/10.1016/j.cofs.2017.06.005.

Pinheiro, A. C., Lad, M., Silva, H. D., Coimbra, M. A., Boland, M., \& Vicente, A. A. (2013). Unravelling the behaviour of curcumin nanoemulsions during in vitro digestion: Effect of the surface charge. Soft Matter, 9(11), 3147. https://doi.org/10.1039/ 
c3sm27527b.

Pool, H., Mendoza, S., Xiao, H., \& McClements, D. J. (2013). Encapsulation and release of hydrophobic bioactive components in nanoemulsion-based delivery systems: Impact of physical form on quercetin bioaccessibility. Food Function, 4(1), 162-174. https:// doi.org/10.1039/C2FO30042G.

Quintanilla-Carvajal, M. X., Camacho-Díaz, B. H., Meraz-Torres, L. S., Chanona-Pérez, J. J., Alamilla-Beltrán, L., Jimenéz-Aparicio, A., \& Gutiérrez-López, G. F. (2010). Nanoencapsulation: A new trend in food engineering processing. Food Engineering Reviews, 2(1), 39-50. https://doi.org/10.1007/s12393-009-9012-6.

Ramos, O. L., Pereira, R. N., Martins, A., Rodrigues, R., Fuciños, C., Teixeira, J. A., ... Vicente, A. A. (2017). Design of Whey Protein Nanostructures for Incorporation and Release of Nutraceutical Compounds in Food. Critical Reviews in Food Science and Nutrition, 57(7), 1377-1393. https://doi.org/10.1080/10408398.2014.993749.

Ramos, Oscar L., Pereira, J. O., Silva, S. I., Amorim, M. M., Fernandes, J. C., Lopes-daSilva, J. A., ... Malcata, F. X. (2012). Effect of composition of commercial whey protein preparations upon gelation at various $\mathrm{pH}$ values. Food Research International, 48(2), 681-689. https://doi.org/10.1016/j.foodres.2012.06.004.

Rein, M. J., Renouf, M., Cruz-Hernandez, C., Actis-Goretta, L., Thakkar, S. K., \& da Silva Pinto, M. (2012). Bioavailability of bioactive food compounds: A challenging journey to bioefficacy. British Journal of Clinical Pharmacology, 75(3), 588-602. https://doi. org/10.1111/j.1365-2125.2012.04425.x.

Ren, Z., Qin, T., Liu, X., Luo, Y., Qiu, F., Long, Y., ... Huang, Y. (2018). Optimization of Hericium erinaceus polysaccharide-loaded Poly (lactic-co-glycolicacid) nanoparticles by RSM and its absorption in Caco-2 cell monolayers. International Journal of Biological Macromolecules, 118, 932-937. https://doi.org/10.1016/j.ijbiomac.2018. 06.169.

Rodrigues, R. M., Martins, A. J., Ramos, O. L., Malcata, F. X., Teixeira, J. A., Vicente, A. A., \& Pereira, R. N. (2015). Influence of moderate electric fields on gelation of whey protein isolate. Food Hydrocolloids, 43, 329-339. https://doi.org/10.1016/j.foodhyd. 2014.06.002.

Samadarsi, R., \& Dutta, D. (2019). Design and characterization of mangiferin nanoparticles for oral delivery. Journal of Food Engineering, 247(August 2018), 80-94. https://doi.org/10.1016/j.jfoodeng.2018.11.020.

Sedaghat Doost, A., Kassozi, V., Grootaert, C., Claeys, M., Dewettinck, K., Van Camp, J., \& Van der Meeren, P. (2019). Self-assembly, functionality, and in-vitro properties of quercetin loaded nanoparticles based on shellac-almond gum biological macromolecules. International Journal of Biological Macromolecules, 129, 1024-1033. https://doi.org/10.1016/j.ijbiomac.2019.02.071.

Shen, C. R., Liu, C. L., Lee, H. P., \& Chen, J. K. (2013). The identification and characterization of chitotriosidase activity in pancreatin from porcine pancreas. Molecules, 18(3), 2978-2987. https://doi.org/10.3390/molecules18032978.

Silva, H. D., Poejo, J., Pinheiro, A. C., Donsì, F., Teresa, A., Duarte, C. M. M., ... Vicente, A. A. (2018). Evaluating the behaviour of curcumin nanoemulsions and multilayer nanoemulsions during dynamic in vitro digestion. Journal of Functional Foods, 48(April), 605-613. https://doi.org/10.1016/j.jff.2018.08.002.

Simões, L. S., Abrunhosa, L., Vicente, A. A., \& Ramos, O. L. (2020). Suitability of $\beta$ lactoglobulin micro- and nanostructures for loading and release of bioactive compounds. Food Hydrocolloids, 105492. https://doi.org/10.1016/j.foodhyd.2019. 105492.

Simões, L. S., Araújo, J. F., Vicente, A. A., \& Ramos, O. L. (2020). Design of $\beta$-lactoglobulin micro- and nanostructures by controlling gelation through physical variables.
Food Hydrocolloids, 100. https://doi.org/10.1016/j.foodhyd.2019.105357.

Singh, H., \& Sarkar, A. (2011). Behaviour of protein-stabilised emulsions under various physiological conditions. Advances in Colloid and Interface Science, 165(1), 47-57. https://doi.org/10.1016/j.cis.2011.02.001.

Spellman, D., McEvoy, E., O'Cuinn, G., \& FitzGerald, R. J. (2003). Proteinase and exopeptidase hydrolysis of whey protein: Comparison of the TNBS, OPA and $\mathrm{pH}$ stat methods for quantification of degree of hydrolysis. International Dairy Journal, 13(6), 447-453. https://doi.org/10.1016/S0958-6946(03)00053-0.

Sullivan, A. C., Pangloli, P., \& Dia, V. P. (2018). Impact of ultrasonication on the physicochemical properties of sorghum kafirin and in vitro pepsin-pancreatin digestibility of sorghum gluten-like flour. Food Chemistry, 240(August 2017), 1121-1130. https:// doi.org/10.1016/j.foodchem.2017.08.046.

Tavares, T., Ramos, O. L., \& Malcata, F. X. (2017). ß-Lactoglobulin microparticles obtained by high intensity ultrasound as a potential delivery system for bioactive peptide concentrate. Journal of Food Science and Technology, 54(13), 4387-4396. https://doi.org/10.1007/s13197-017-2912-1.

Tibolla, H., Pelissari, F. M., Martins, J. T., Lanzoni, E. M., Vicente, A. A., Menegalli, F. C., \& Cunha, R. L. (2019). Banana starch nanocomposite with cellulose nanofibers isolated from banana peel by enzymatic treatment: In vitro cytotoxicity assessment. Carbohydrate Polymers, 207(November 2018), 169-179. https://doi.org/10.1016/j carbpol.2018.11.079.

Tibolla, H., Pelissari, F. M., Martins, J. T., Vicente, A. A., \& Menegalli, F. C. (2018) Cellulose nanofibers produced from banana peel by chemical and mechanical treatments: Characterization and cytotoxicity assessment. Food Hydrocolloids, 75, 192-201. https://doi.org/10.1016/j.foodhyd.2017.08.027.

Ting, Y., Jiang, Y., Ho, C.-T., \& Huang, Q. (2014). Common delivery systems for enhancing in vivo bioavailability and biological efficacy of nutraceuticals. Journal of Functional Foods, 7(1), 112-128. https://doi.org/10.1016/j.jff.2013.12.010.

Tseng, Y. M., Lin, S. K., Hsiao, J. K., Chen, I. J., Lee, J. H., Wu, S. H., \& Tsai, L. Y. (2006) Whey protein concentrate promotes the production of glutathione (GSH) by GSH reductase in the PC12 cell line after acute ethanol exposure. Food and Chemical Toxicology, 44(4), 574-578. https://doi.org/10.1016/j.fct.2005.09.003.

Wang, S., Su, R., Nie, S., Sun, M., Zhang, J., Wu, D., \& Moustaid-Moussa, N. (2014a). Application of nanotechnology in improving bioavailability and bioactivity of dietderived phytochemicals. Journal of Nutritional Biochemistry, 25(4), 363-376. https:// doi.org/10.1016/j.jnutbio.2013.10.002.

Wang, Y., Yuan, L., Yao, C., Ding, L., Li, C., Fang, J., ... Wu, M. (2014b). A combined toxicity study of zinc oxide nanoparticles and vitamin $\mathrm{C}$ in food additives. Nanoscale, 6(24), 15333-15342. https://doi.org/10.1039/c4nr05480f.

Yi, J., Zhong, F., Zhang, Y., Yokoyama, W., \& Zhao, L. (2015). Effects of Lipids on in Vitro Release and Cellular Uptake of $\beta$-Carotene in Nanoemulsion-Based Delivery Systems. Journal of Agricultural and Food Chemistry, 63(50), 10831-10837. https://doi.org/10. 1021 /acs.jafc.5b04789.

Zagury, Y., Kazir, M., \& Livney, Y. D. (2019). Improved antioxidant activity, bioaccessibility and bioavailability of EGCG by delivery in $\beta$-lactoglobulin particles. Journal of Functional Foods, 52(October 2018), 121-130. https://doi.org/10.1016/j.jff.2018.10. 025.

Zhang, S., \& Vardhanabhuti, B. (2014). Effect of initial protein concentration and pH on in vitro gastric digestion of heated whey proteins. Food Chemistry, 145, 473-480. https://doi.org/10.1016/j.foodchem.2013.08.076. 